ҚАЗАҚСТАН РЕСПУБЛИКАСЫ

ҰЛТТЫҚ ҒЫЛЫМ АКАДЕМИЯСЫНЫҢ

Өсімдіктердің биологиясы және биотехнологиясы институтының

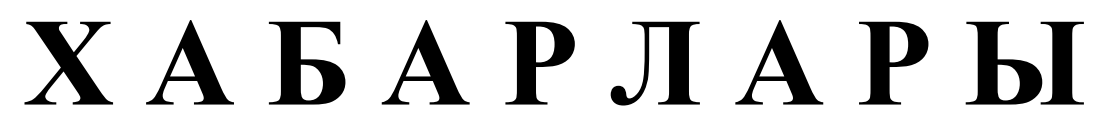

\section{ИЗВЕСТИЯ}

НАЦИОНАЛЬНОЙ АКАДЕМИИ НАУК РЕСПУБЛИКИ КАЗАХСТАН

Института биологии и биотехнологии растений

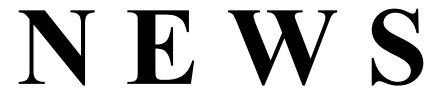

OF THE NATIONAL ACADEMY OF SCIENCES OF THE REPUBLIC OF KAZAKHSTAN of the Institute of Plant Biology and Biotechnology

БИОЛОГИЯ ЖӘНЕ МЕДИЦИНА

СЕРИЯСЫ

$\checkmark$

СЕРИЯ

БИОЛОГИЧЕСКАЯ И МЕДИЦИНСКАЯ

SERIES

OF BIOLOGICAL AND MEDICAL

\title{
5 (329)
}

ҚЫРКУЙЕК - ҚАЗАН 2018 ж.

СЕНТЯБРЬ - ОКТЯБРЬ 2018 Г.

SEPTEMBER - OCTOBER 2018

1963 ЖЫЛДЫҢ ҚАНТАР АЙЫНАН ШЫҒА БАСТАҒАН

ИЗДАЕТСЯ С ЯНВАРЯ 1963 ГОДА

PUBLISHED SINCE JANUARY 1963

ЖЫЛЫНА 6 РЕТ ШЫҒАДЫ

ВЫХОДИТ 6 РАЗ В ГОД

PUBLISHED 6 TIMES A YEAR 
ҚР ҰҒА академигі, м. ғ. д., проф. Ж. А. Арзыкұлов

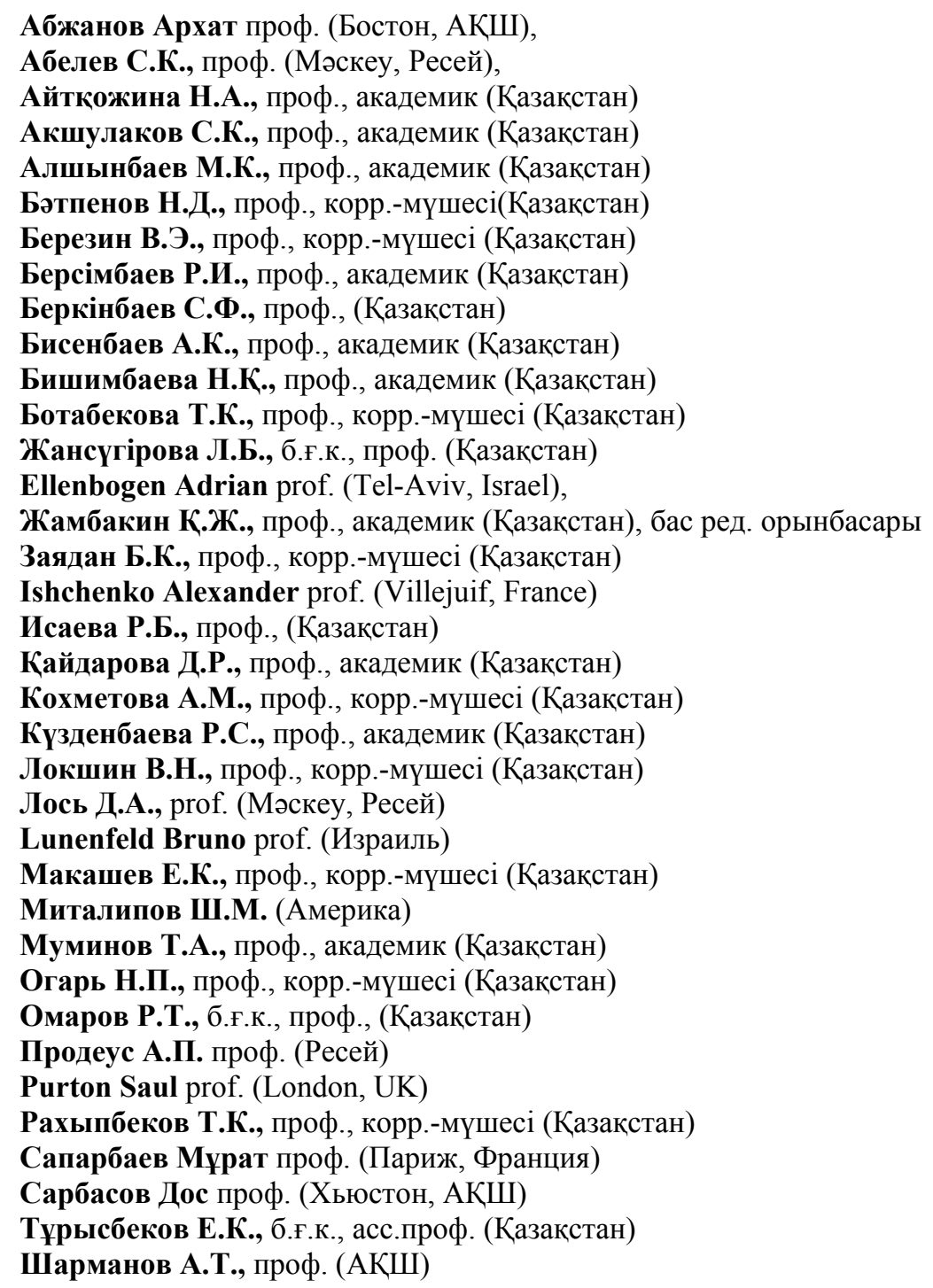

«ҚР ҰҒА Хабарлары. Биология және медициналық сериясы». ISSN 2518-1629 (Online), ISSN 2224-5308 (Print)

Меншіктенуші: «Қазақстан Республикасының Ұлттық ғылым академиясы» РҚБ (Алматы қ.)

Қазақстан республикасының Мәдениет пен ақпарат министрлігінің Ақпарат және мұрағат комитетінде 01.06.2006 ж. берілген №5546-Ж мерзімдік басылым тіркеуіне қойылу туралы куәлік

Мерзімділігі: жылына 6 рет.

Тиражы: 300 дана.

Редакцияның мекенжайы: 050010, Алматы қ., Шевченко көш., 28, 219 бөл., 220, тел.: 272-13-19, 272-13-18, www:nauka-nanrk.kz / biological-medical.kz

Типографияның мекенжайы: «Аруна» ЖК, Алматы қ., Муратбаева көш., 75. 
академик НАН РК, д.м.н., проф. Ж. А. Арзыкулов

Абжанов Архат проф. (Бостон, США),

Абелев С.К. проф. (Москва, Россия),

Айтхожина Н.А. проф., академик (Казахстан)

Акшулаков С.К. проф., академик (Казахстан)

Алчинбаев М.К. проф., академик (Казахстан)

Батпенов Н.Д. проф. член-корр.НАН РК (Казахстан)

Березин В.Э., проф., чл.-корр. (Казахстан)

Берсимбаев Р.И., проф., академик (Казахстан)

Беркинбаев С.Ф. проф. (Казахстан)

Бисенбаев А.К. проф., академик (Казахстан)

Бишимбаева Н.К. проф., академик (Казахстан)

Ботабекова Т.К. проф., чл.-корр. (Казахстан)

Джансугурова Л. Б. к.б.н., проф. (Казахстан)

Ellenbogen Adrian prof. (Tel-Aviv, Israel),

ЖамбакинК.Ж. проф., академик (Казахстан), зам. гл. ред.

Заядан Б.К. проф., чл.-корр. (Казахстан)

Ishchenko Alexander, prof. (Villejuif, France)

Исаева Р.Б. проф. (Казахстан)

Кайдарова Д.Р. проф., академик (Казахстан)

Кохметова А.М. проф., чл.-корр. (Казахстан)

Кузденбаева Р.С. проф., академик (Казахстан)

Локшин В.Н., проф., чл.-корр. (Казахстан)

Лось Д.А. prof. (Москва, Россия)

Lunenfeld Bruno prof. (Израиль)

Макашев Е.К. проф., чЛ.-корр. (Казахстан)

Миталипов Ш.М. (Америка)

Муминов Т.А. проф., академик (Казахстан)

Огарь Н.П. проф., чл.-корр. (Казахстан)

Омаров Р.Т.к.б.н., проф. (Казахстан)

Продеус А.П. проф. (Россия)

Purton Saul prof. (London, UK)

Рахыпбеков Т.К. проф., чл.-корр. (Казахстан)

Сапарбаев Мурат проф. (Париж, Франция)

Сарбасов Дос проф. (Хьюстон, США)

Турысбеков Е. К., к.б.н., асс.проф. (Казахстан)

Шарманов А.Т. проф. (США)

\section{«Известия НАН РК. Серия биологическая и медицинская». \\ ISSN 2518-1629 (Online), \\ ISSN 2224-5308 (Print)}

Собственник: РОО «Национальная академия наук Республики Казахстан» (г. Алматы)

Свидетельство о постановке на учет периодического печатного издания в Комитете информации и архивов

Министерства культуры и информации Республики Казахстан №5546-Ж, выданное 01.06.2006 г.

Периодичность: 6 раз в год

Тираж: 300 экземпляров

Адрес редакции: 050010, г. Алматы, ул. Шевченко, 28, ком. 219, 220, тел. 272-13-19, 272-13-18, www:nauka-nanrk.kz / biological-medical.kz 


\section{Editor in chief}

Zh.A. Arzykulov, academician of NAS RK, Dr. med., prof.

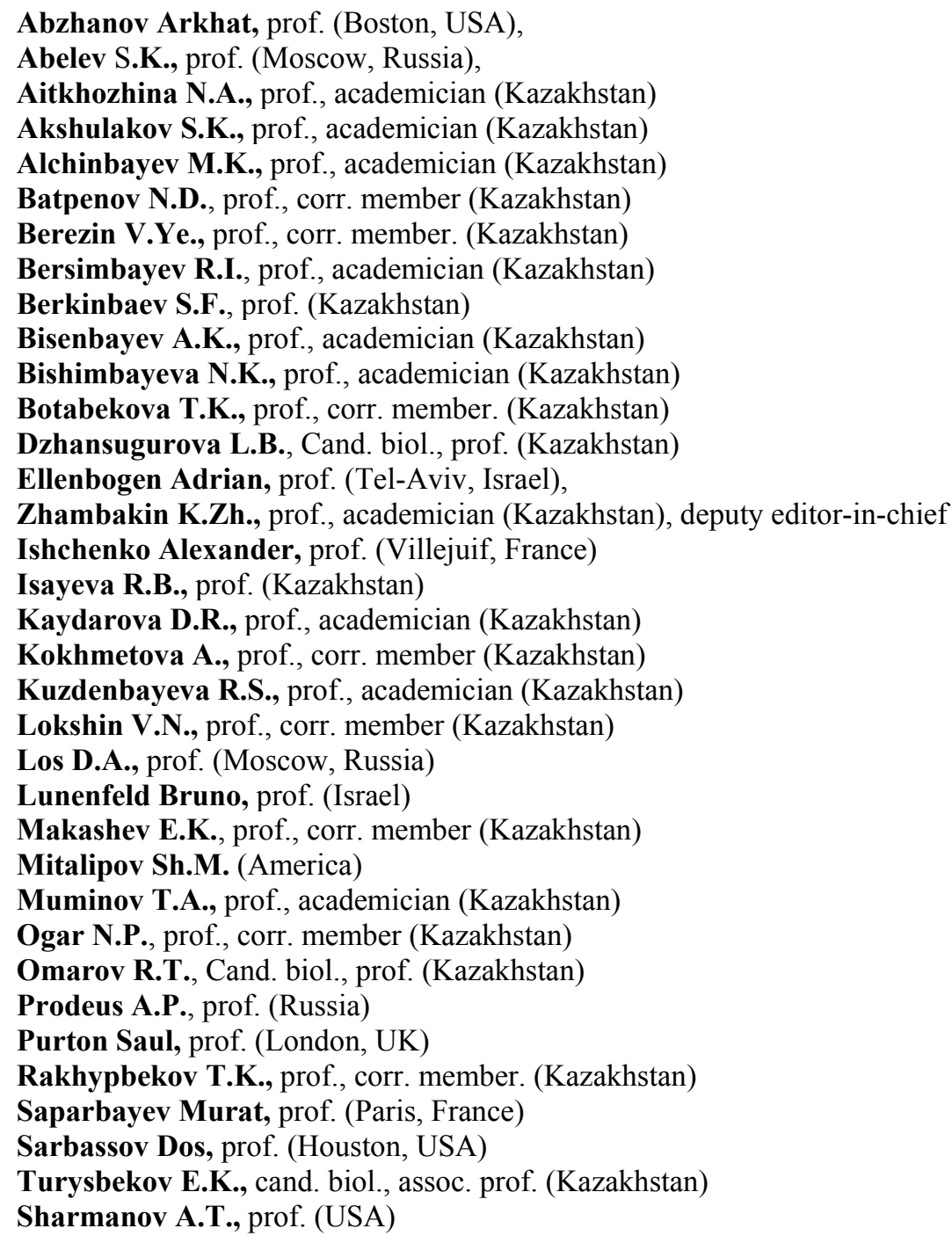

News of the National Academy of Sciences of the Republic of Kazakhstan. Series of biology and medicine. ISSN 2518-1629 (Online), ISSN 2224-5308 (Print)

Owner: RPA "National Academy of Sciences of the Republic of Kazakhstan" (Almaty)

The certificate of registration of a periodic printed publication in the Committee of information and archives of the Ministry of culture and information of the Republic of Kazakhstan N 5546-Ж, issued 01.06.2006

Periodicity: 6 times a year

Circulation: 300 copies

Editorial address: 28, Shevchenko str., of. 219, 220, Almaty, 050010, tel. 272-13-19, 272-13-18, http://nauka-nanrk.kz / biological-medical.kz

(C) National Academy of Sciences of the Republic of Kazakhstan, 2018

Address of printing house: ST "Aruna", 75, Muratbayev str, Almaty 


\title{
N E W S
}

OF THE NATIONAL ACADEMY OF SCIENCES OF THE REPUBLIC OF KAZAKHSTAN

SERIES OF BIOLOGICAL AND MEDICAL

ISSN 2224-5308

https://doi.org/10.32014/2018.2518-1629.4

Volume 5, Number 329 (2018), 25 - 36

МНРТИ 34.23.35

UDC 575.17

L. B. Djansugurova, G. S. Zhunusova, Nurzhibek,

\section{S. A. Abdikerim, A. S. Amirgaliyeva, B. O. Bekmanov, E. M. Khussainova}

\author{
Laboratory of population genetics, RSE "Institute of General Genetics and Cytology" CS MES RK, Almaty, \\ Kazakhstan. \\ E-mail: leylad@mail.ru, gulnur_j@mail.ru, kahbatnur64@gmail.com, abdikerim.saltanat1@gmail.com, almira- \\ 71@mail.ru, bobekman@rambler.ru
}

\section{MtDNA CONTROL REGIONS ANALYSIS AT ETHNIC KAZAKHS}

\begin{abstract}
The analysis of mitochondrial DNA of modern Kazakhs with a wide geographic localization and tribal affiliation shows that the Kazakh's maternal lines are characterized by great diversity of mtDNA haplogroups, reflecting the historical migration of the population of Eurasia with the predominance of "Asian" and "European" components. The analysis of mutations of hypervariable regions of mtDNA (HVR1, HVR2) regarding affiliation to Zhuz determines the genetic affinity of all Kazakh maternal lines.
\end{abstract}

Keywords: modern Kazakh, mtDNA, HVR1, HVR2, haplogroup.

Due to intensive studies over the past decades, considerable data on the DNA polymorphism in human populations have been accumulated. A variety of polymorphic markers are used to analyze the gene pool of populations and individual ethnic groups, determine their basic characteristics, dynamics, history and geography. There are high polymorphic loci of coding genes, insertion-deletion polymorphism, micro- and minisatellite, single-nucleotide substitution (SNP), and copy number variants (CNV).

The Y-chromosome and mitochondrial DNA (mtDNA) polymorphisms have become widely used genetic markers in population studies related to the genogeography and Human history because they reflect the inheritance and variability of paternal and maternal lines. The mtDNA polymorphism characterizes the absence of recombinations and the maternal type of inheritance. In this regard, the mitochondrial genome can evolve only through the successive accumulation of mutations in generations. In the mitochondrial genome, two main areas are identified: the coding region and the non-coding region (D-loop). The non-coding region is the most variable region of mtDNA and contains about $23 \%$ of the variations in the entire mitochondrial genome. About $30 \%$ of the variability of mtDNA associates with interpopulation and intergroup differences. In comparison with the nuclear genome, the mtDNA mutation rate determined the advantages of mitochondrial DNA in front of nuclear genetic markers, which make it possible to use it as a tool for population-genetic studies.

To date, there are huge data on population-based mtDNA polymorphism in many modern and ancient human populations. In this respect, the most studied are the peoples of the New World, Africa, Southeast Asia and Oceania, as well as Western Europe. At the same time, polymorphism of the mitochondrial genome of Turkic-speaking peoples, one of the vast and most ancient ethnic groups in Eurasia, has been little studied.

The ethnogenesis of the Kazakh people is based on historical, demographic, population-genetic and anthropological background, conditioned by the influence of the Aryan, Indo-Iranian and Turkic tribes, from Saks, Sarmatians, Massagets to Huns, Turks, Karluks, Oguzes, Kimaks, Kipchaks and other ethnic groups. Later Turkic-Mongolian tribes later formed a Kazakh ethnos, known since the 15th century. 
A few genetic studies of archaeological material and modern populations from Kazakhstan [1-5] testify the genetic homogeneity of modern Kazakhs, which makes it possible to differentiate the Kazakh people from other Eurasian population, despite the wide polymorphism and intrapopulation diversity.

The usage of mtDNA markers indicates a high heterogeneity of mtDNA haplogroups among Kazakhs and suggests that $55 \%$ of Kazakh mtDNA haplogroups originated from Eastern Eurasia, while $41 \%$ are from Western Eurasia [2-5]. Some authors point to the similarity of mtDNA haplotypes of modern Kazakhs with barrow cultures of the 1 st millennium BC [5, 6]. A study of 304 Kazakhs with a wide geographic distribution (10 populations of rural residents) revealed that 58-59\% of Kazakhs exhibit Asian mtDNA haplotypes (D, C, G, A, M and F) and 41\% European (H, T, J, K, U2, I, U5 and HVR) [3, 7]. Based on the variability of the hypervariable region of mtDNA (HVR1) analysis of the genetic relationships of different Asian populations, which was performed on a large sample size (33 groups, about 3,000 samples), showed the genetic relationship of Altai Kazakhs with other ethnic groups from Altai (Kalmyks, Soyots, Hamnigans, Buryats, Tolengites and other Altai peoples) [7-9]. The distinct differences in the nature of genetic variability between the maternal and paternal genetic lines among Altai Kazakhs (119 individuals) was noticed by Dulik M.S. with co-authors [10]. While on the maternal line the mtDNA haplotypes widespread in the East and West Europe were determined, the paternal type of inheritance demonstrated a low genetic diversity. Population-genetic study of the Y-chromosome and mtDNA of 160 representatives of the Kazakh tribe Naiman showed that maternal lines represent high migration activity and the diversity of mtDNA [11].

So, the most studies were conducted on a representatives of separate tribe or specialized geographically location. To replenish the information about maternal lines of modern Kazakhs we conducted a research of a selected cohort with high tribal affiliation and geographic distribution.

Materials and methods. Study objects. The study objects were data of questionnaires, EDTA-treated peripheral blood samples which were taken from 96 modern Kazakhs with different tribal affiliation and geographic localization. Before collection of blood samples we asked people the voluntary consent to participate in genetic research. A detailed questioning was done after obtaining the signed voluntary informed consents. The knowledge of the maternal line history was the main selection criterium for the study. Questionnaires included the information on the paternal and maternal tribal affiliation of the persons (shezhire).

Extraction of DNA. Genomic DNA was extracted from EDTA-treated peripheral blood samples using "Genomic DNA Purification Kit" (Thermo Scientific). Qualitative and quantitative characteristics of the DNA samples were estimated using Eppendorf BioPhotometer plus (Eppendorf, Germany) or NanoDrop 2000 (Thermo Scientific, USA). DNA samples were stored at $-20^{\circ} \mathrm{C}$.

Mitochondrial DNA analysis. Sequencing of the hypervariable regions of mtDNA (HVR1, HVR2), as well as complete mtDNA sequencing, were performed using a next generation sequencing (NGS) analyzer MiSeq (Illumina, San Diego, USA).

PCR amplification, for the creation of four amplicons (nucleotide positions: 29-285, 172-408, 1599716236 and 16159-16401) representing the 2 hypervariable regions of the ring mitochondrial DNA (HVR1, HVR2), was performed in four separate reactions on a single sample using a kit "Human mtDNA D-Loop Hypervariable Region" (Illumina, San Diego, USA). The quantity and quality of PCR amplicons were determined by electrophoresis and the Quantus TM Fluorometer. The DNA amplicons were normalized to $0.2 \mathrm{ng} / \mu 1$ and combined in a ratio of 1: 1: 1: 1 in a total volume of $20 \mu 1(5 \mu \mathrm{lech})$. The DNA libraries for sequencing were obtained from normalized PCR products (1 ng total input) using the "Next Era XT DNA Sample Preparation" kit (Illumina, San Diego, USA) in accordance with the manufacturer's guidelines. The mtDNA samples were combined with $25 \%$ PhiX control and were sequenced at a concentration of 10 pM according to the manufacturer's instructions in $2 \times 151$ cycles.

Bioinformatic and statistical analysis. The MiSeq data was analyzed using the mtDNA MiSeq Reporter (MSR) plug-in, and interpreted using the BaseSpace ${ }^{\circledR}$ mtDNA Variant Processor v1.0 App (Illumina, San Diego, USA) software. This program allows to align and order the sequenced sequences which are matched to the reference sequence of the full mtDNA genome - Cambridge Reference Sequence (rCRS) [12]. The program allows to analyze any part of the complete genome of the ring mtDNA using a quality and overlapping coverage (Quality for variant call Q30) with the identification of start points. To use this program, the primary sequencing data obtained in the FASTQ format (mtDNA MiSeq Reporter) 
were converted into BAM and VCF formats. For identification of mtDNA haplotypes we used the Haplogrep programs (version 2.0, https://haplogrep.uibk.ac.at/), Haplofind (https://haplofind.unibo.it) and mtDNA manager [13]. Mutation frequencies, molecular difference analysis and pairwise genetic distances were calculated using the GeneAlEx 6.2 program. Phylogenetic relationships were defined using the MEGA7 program.

Results and their discussion. The selection a cohort for the study was determined by the availability of personal data on the maternal lines of inheritance. At the same time, we were oriented to the fact that at least 2 generations (mother and grandmother) would belong to the same clan by maternal inheritance. Also we have count the wide geography distributions and tribal affiliation. Thus, 96 persons were selected, who belonging to different families and having different geographical localization. Among them were 55 men and 41 women.

The table S1 (Application 1) presents our data on shezhire, mtDNA control region mutations (HVR1 \& HVR2) and sex of investigated individuals. The diversity of mtDNA haplotypes in cohort of modern Kazakhs with different tribal affiliations and geographical localization is shown on figure 1.

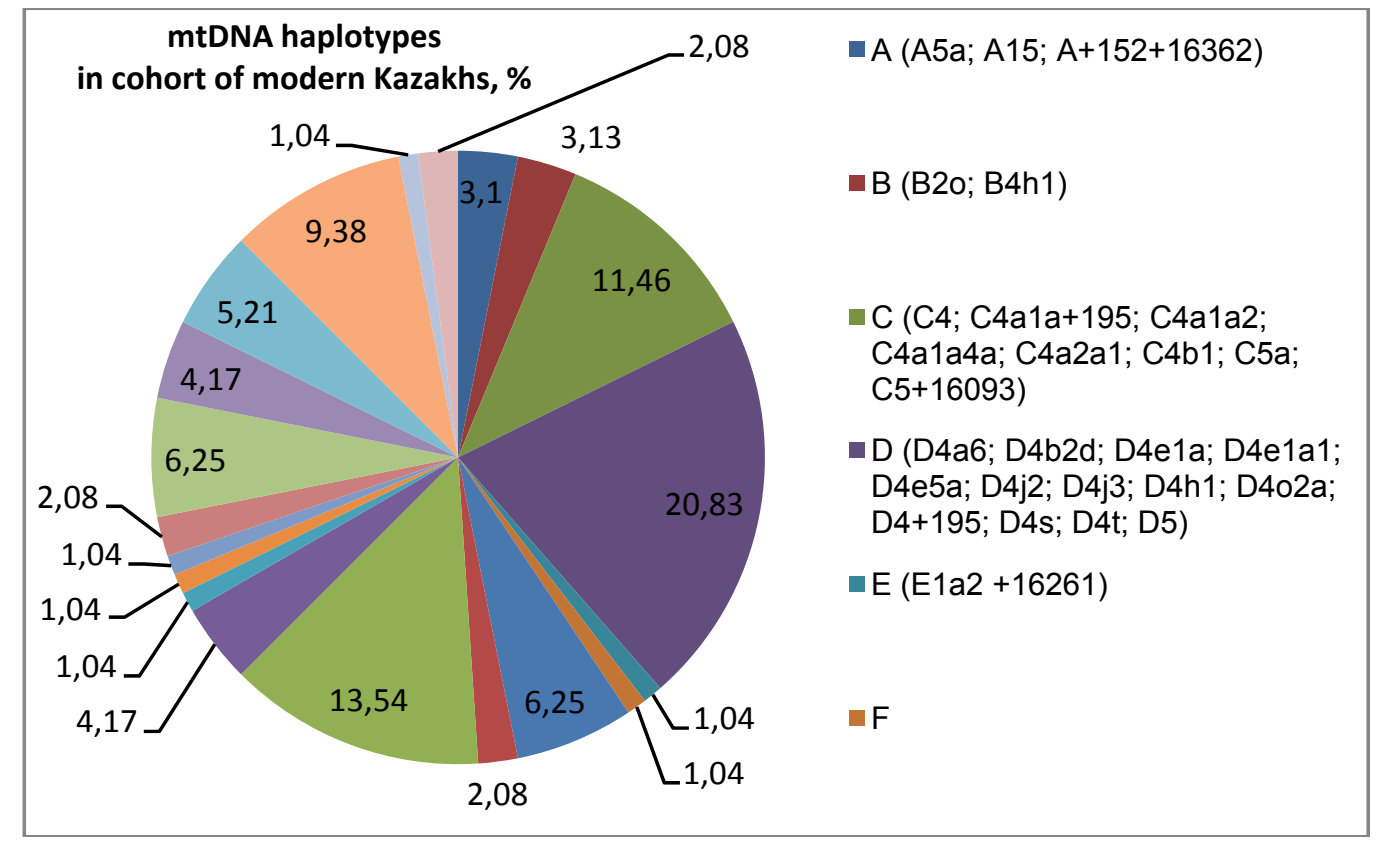

Figure 1 - mtDNA haplotypes in cohort of modern Kazakhs

In total, 81 haplotypes of mtDNA were identified in the studied cohort:

1) A5a; A15; A+152+16362; B2o; C4; C4a1a2; C4a1a4a; C4b1; C5a; C5+16093; D4a6; D4b2d; D4e1a; D4j2; D4h1; D4o2a; D4s; E1a2 +16261; F; G2a2; G2a5; I1; I1a; H1e1a4; H1+16189; H1ao; H1b; H1e2c; H1e-16129; H2a+152+16311; H2a2a; H2a2a2; H7a1; H13a1d; HV4b; J1c16; J1d; J2b1c1; JT; K1c; L3h1a2a; Z+152 (M8); M6; M10a1a1b; N1a3a; N9a2'4'5'11; R2; R7; R8; R31; T; T1a1; T1a1'3; T2; T2b11; U1a3; U1b2; U2e1h; U2e1b; U2e1'2'3'; U3a3; U4; U4b1b1c; U5a2+1629; X2; W3; W4 - for 1 person from studied individuals $(1,04 \%)$

2) B4h1, C4a2a1; D4e1a1; D4e5a; D4j3; D4+195; D5; G2a; G2a+152; - for 2 persons $(2,08 \%)$;

3) $\mathrm{C} 4 \mathrm{a} 1 \mathrm{a}+195$; $\mathrm{D} 4 \mathrm{t}$; - for 3 persons $(3,13 \%)$;

4) $\mathrm{N} 9 \mathrm{a}$ - for 4 persons $(4,17 \%)$.

As can be seen from presented data, the highest frequency is typical for the D mtDNA haplogroup, which together with the subclades (D4a6, D4b2d, D4e1a, D4e1a1, D4e5a, D4j2, D4j3, D4h1, D4o2a, D4+195, D4s, D4t, D5) represents 20 individuals (20,83\%). Subclades of haplogroup H (H1e1a4, H1+16189, H1ao, H1b, H1e2c, H1e-16129, H2a+152+16311, H2a2a, H2a2a2, H7a1, H13a1d, HV4b) were identified in 13 individuals (13,54\%). Another most distribted hapogroup of mtDNA is C (11 persons $-11,46 \%$ ), which represented in studied cohort by subclades of C4, C4a1a+195, C4a1a2, C4a1a4a, C4a2a1, C4b1, C5a, and C5+16093. 
Известия Национальной академии наук Республики Казахстан

\section{Application 1}

Table S1 - Haplotypes of mtDNA of studied cohort regarding the tribal affiliation of modern Kazakh individuals

\begin{tabular}{|c|c|c|c|c|c|c|c|c|}
\hline \multicolumn{4}{|c|}{ Maternal line } & \multirow{2}{*}{ Haplotype } & \multicolumn{2}{|c|}{ mtDNA mutations } & \multirow{2}{*}{ Gender } & \multirow{2}{*}{$\begin{array}{l}\text { No. } \\
\text { of } \\
\text { ind. }\end{array}$} \\
\hline Tribe & Subtribe & Clan & Subclan & & HVR1 & HVR1 & & \\
\hline \multicolumn{9}{|l|}{ Uly zhuz } \\
\hline Zhalaiyr & Andas & Borte & & D4e1a1 & $\begin{array}{l}\text { 16093C, 16176T, } \\
16223 \mathrm{~T}, 16362 \mathrm{C}\end{array}$ & $\begin{array}{c}\text { 73G, 94A, 194T, 263G, } \\
315.1 \mathrm{C}\end{array}$ & male & 1 \\
\hline Dulat & $?$ & & & H1e-16129 & $16129 \mathrm{~A}$ & $263 \mathrm{G}, 309.1 \mathrm{C}, 315.1 \mathrm{C}$ & male & 1 \\
\hline Saty & $?$ & & & U2e1'2'3 & $\begin{array}{l}16051 \mathrm{G}, 16129 \mathrm{C}, \\
16182 \mathrm{~d}, 16183 \mathrm{C}, \\
16189 \mathrm{C}, 16362 \mathrm{C}\end{array}$ & $\begin{array}{c}73 \mathrm{G}, 152 \mathrm{C}, 217 \mathrm{C} \\
263 \mathrm{G}, 315.1 \mathrm{C}\end{array}$ & female & 1 \\
\hline Alban & Alaman & & & D4+195 & $16218 \mathrm{~T}, 16223 \mathrm{~T}$ & $73 \mathrm{G}, 195 \mathrm{C}, 263 \mathrm{G}, 315.1 \mathrm{C}$ & female & 2 \\
\hline Kanly & $?$ & & & $\mathrm{~J} 1 \mathrm{c} 16$ & $\begin{array}{c}16069 \mathrm{~T}, 16126 \mathrm{C}, \\
16218 \mathrm{~T}\end{array}$ & $\begin{array}{c}73 \mathrm{G}, 152 \mathrm{C}, 185 \mathrm{~A}, 228 \mathrm{~A} \\
263 \mathrm{G}, 309.1 \mathrm{C}, 315.1 \mathrm{C}\end{array}$ & male & 1 \\
\hline \multicolumn{9}{|l|}{ Oshakty } \\
\hline Atalyk & Alimbet & Biguly & Karasirak & N9a & $\begin{array}{c}\text { 16223T, 16257A, } \\
16261 \mathrm{~T}\end{array}$ & $73 \mathrm{G}, 150 \mathrm{~T}, 263 \mathrm{G}, 315.1 \mathrm{C}$ & female & 1 \\
\hline Konyr & $?$ & & & $\mathrm{C} 5 \mathrm{a}$ & $\begin{array}{l}16223 \mathrm{~T}, 16261 \mathrm{~T}, \\
16288 \mathrm{C}, 16298 \mathrm{C}\end{array}$ & $73 \mathrm{G}, 249 \mathrm{~d}, 263 \mathrm{G}, 315.1 \mathrm{C}$ & male & 1 \\
\hline Taszhurek & $?$ & & & $\mathrm{~J} 1 \mathrm{c} 2$ & $16126 \mathrm{C}$ & $\begin{array}{c}\text { 73G, } 185 \mathrm{~A}, 188 \mathrm{G}, 228 \mathrm{~A} \\
263 \mathrm{G}, 295 \mathrm{~T}, 309.2 \mathrm{C} \\
315.1 \mathrm{C} \\
\end{array}$ & male & 1 \\
\hline $\begin{array}{l}\text { Uisun (Sary } \\
\text { uisun) }\end{array}$ & $?$ & & & $\mathrm{D} 4 \mathrm{j} 3$ & $\begin{array}{l}16184 \mathrm{~T}, 16223 \mathrm{~T}, \\
16311 \mathrm{C}, 16362 \mathrm{C}\end{array}$ & $\begin{array}{c}73 \mathrm{G}, 146 \mathrm{C}, 227 \mathrm{~T}, 263 \mathrm{G}, \\
309.2 \mathrm{C}, 310 \mathrm{C}, 315.1 \mathrm{C}\end{array}$ & male & 1 \\
\hline Zhakyp & $?$ & & & Ila & $\begin{array}{c}16129 \mathrm{~A}, 16172 \mathrm{C}, \\
16223 \mathrm{~T}\end{array}$ & $\begin{array}{c}\text { 73G, } 195 \mathrm{C}, 199 \mathrm{C}, 203 \mathrm{~A} \\
204 \mathrm{C}, 250 \mathrm{C}, 263 \mathrm{G} \\
309.1 \mathrm{C}, 315.1 \mathrm{C}\end{array}$ & female & 1 \\
\hline Pusyrman & $?$ & & & $\mathrm{~T} 2$ & $\begin{array}{c}16078 \mathrm{G}, 16126 \mathrm{C}, \\
16177 \mathrm{G}, 16294 \mathrm{~T}, \\
16296 \mathrm{~T}\end{array}$ & $73 \mathrm{G}, 263 \mathrm{G}, 315.1 \mathrm{C}$ & female & 1 \\
\hline Suan & Aksham & & & $\mathrm{C} 4$ & $\begin{array}{c}16223 \mathrm{~T}, 16298 \mathrm{C}, \\
16327 \mathrm{~T}\end{array}$ & $\begin{array}{c}73 \mathrm{G}, 152 \mathrm{C}, 195 \mathrm{C}, 248 \mathrm{~d}, \\
263 \mathrm{G}, 315.1 \mathrm{C}\end{array}$ & male & 1 \\
\hline \multicolumn{9}{|l|}{ Shaprashty } \\
\hline Ikei & Kosai & & & C4a1a2 & $\begin{array}{c}16093 \mathrm{C}, 16129 \mathrm{~A}, \\
16223 \mathrm{~T}, 16298 \mathrm{C}, \\
16327 \mathrm{~T} \\
\end{array}$ & $\begin{array}{c}73 \mathrm{G}, 195 \mathrm{C}, 248 \mathrm{~d}, 263 \mathrm{G} \\
315.1 \mathrm{C}\end{array}$ & female & 1 \\
\hline Eskozha & Baba & & & $\mathrm{C} 4 \mathrm{~b} 1$ & $\begin{array}{c}16223 \mathrm{~T}, 16298 \mathrm{C} \\
16327 \mathrm{~T}\end{array}$ & $\begin{array}{c}73 \mathrm{G}, 146 \mathrm{C}, 234 \mathrm{G}, 248 \mathrm{~d} \\
249 \mathrm{~A}, 263 \mathrm{G}, 309.1 \mathrm{C} \\
309.2 \mathrm{C}, 315.1 \mathrm{C}\end{array}$ & male & 1 \\
\hline Koshek & Alshan & & & $\mathrm{H} 7 \mathrm{a} 1$ & $16126 \mathrm{C}, 16261 \mathrm{~T}$ & $263 \mathrm{G}, 309.1 \mathrm{C}, 315.1 \mathrm{C}$ & female & 1 \\
\hline Ysty & Tilik & & & $\mathrm{U} 1 \mathrm{~b} 2$ & $\begin{array}{c}16111 \mathrm{~T}, 16214 \mathrm{~A}, \\
16231 \mathrm{C}, 16249 \mathrm{C}, \\
16327 \mathrm{~T} \\
\end{array}$ & $\begin{array}{c}73 \mathrm{G}, 146 \mathrm{C}, 152 \mathrm{C}, 263 \mathrm{G} \\
285 \mathrm{~T}, 309.1 \mathrm{C}, 315.1 \mathrm{C}\end{array}$ & male & 1 \\
\hline \multicolumn{9}{|l|}{ Shanyshkyly } \\
\hline Arynshi & $?$ & & & T1a1 & $\begin{array}{c}16126 \mathrm{C}, 16163 \mathrm{G}, \\
16186 \mathrm{~T}, 16189 \mathrm{C}, \\
16294 \mathrm{~T} \\
\end{array}$ & $\begin{array}{c}73 \mathrm{G}, 152 \mathrm{C}, 195 \mathrm{C}, 263 \mathrm{G} \\
309.1 \mathrm{C}, 315.1 \mathrm{C}\end{array}$ & male & 1 \\
\hline Katagan & $?$ & & & G2a5 & $\begin{array}{c}16093 \mathrm{C}, 16223 \mathrm{~T}, \\
16227 \mathrm{G}, 16234 \mathrm{~T}, \\
16278 \mathrm{~T}, 16309 \mathrm{G}, \\
16362 \mathrm{C}\end{array}$ & $73 \mathrm{G}, 152 \mathrm{C}, 263 \mathrm{G}, 315.1 \mathrm{C}$ & male & 1 \\
\hline Mamyt & $?$ & & & $\mathrm{~K} 1 \mathrm{c}$ & $16224 \mathrm{C}, 16311 \mathrm{C}$ & $\begin{array}{c}73 \mathrm{G}, 146 \mathrm{C}, 152 \mathrm{C}, 263 \mathrm{G}, \\
315.1 \mathrm{C}\end{array}$ & male & 1 \\
\hline \multicolumn{9}{|l|}{ Orta zhuz } \\
\hline Argyn & $?$ & & & U3a3 & $\begin{array}{c}16148 \mathrm{~T}, 16189 \mathrm{C}, \\
16343 \mathrm{G}, 16355 \mathrm{~T}, \\
16390 \mathrm{~A}\end{array}$ & $73 \mathrm{G}, 185 \mathrm{~A}, 263 \mathrm{G}, 315.1 \mathrm{C}$ & male & 1 \\
\hline
\end{tabular}




\begin{tabular}{|c|c|c|c|c|c|c|c|c|}
\hline & Saidaly & & & N1a3a & $\begin{array}{c}16201 \mathrm{~T}, 16223 \mathrm{~T} \\
16265 \mathrm{G}\end{array}$ & $\begin{array}{c}73 \mathrm{G}, 189 \mathrm{G}, 195 \mathrm{C}, 204 \mathrm{C} \\
207 \mathrm{~A}, 210 \mathrm{G}, 263 \mathrm{G} \\
315.1 \mathrm{C} \\
\end{array}$ & female & 1 \\
\hline & Tolengit & & & M6 & $16223 \mathrm{~T}, 16362 \mathrm{C}$ & $73 \mathrm{G}, 195 \mathrm{~T}, 263 \mathrm{G} 315.1 \mathrm{C}$ & male & 1 \\
\hline \multirow{22}{*}{ Meiram } & \multirow{11}{*}{ Suindik } & \multirow{4}{*}{ Karzhas } & & $\mathrm{H} 33 \mathrm{c}$ & $16188 \mathrm{~T}$ & $263 \mathrm{G}, 315.1 \mathrm{C}$ & female & 1 \\
\hline & & & & D4b2d & $\begin{array}{c}16223 \mathrm{~T}, 16274 \mathrm{~A}, \\
16278 \mathrm{~T} 16287 \mathrm{~T}, \\
16362 \mathrm{C} \\
\end{array}$ & $\begin{array}{c}73 \mathrm{G}, 151 \mathrm{~T}, 152 \mathrm{C}, 237 \mathrm{G} \\
263 \mathrm{G}, 315.1 \mathrm{C}\end{array}$ & male & 1 \\
\hline & & & & U2e1h & $\begin{array}{l}\text { 16051G, 16129C, } \\
16183 \mathrm{C}, 16193.1 \mathrm{C}\end{array}$ & $\begin{array}{c}\text { 73G, 195C, 217C, } 228 \mathrm{~A} \\
263 \mathrm{G}, 309.1 \mathrm{C}, 309.2 \mathrm{C} \\
315.1 \mathrm{C}, 340 \mathrm{~T}\end{array}$ & male & 1 \\
\hline & & & \begin{tabular}{|c|} 
Khangeldi- \\
Kushik
\end{tabular} & H13a1d & $16234 \mathrm{~T}$ & $\begin{array}{c}152 \mathrm{C}, 263 \mathrm{G}, 309.1 \mathrm{C} \\
315.1 \mathrm{C} \\
\end{array}$ & male & 1 \\
\hline & & \multirow{5}{*}{ Kulboldy } & $\begin{array}{l}\text { Aidabol- } \\
\text { Tulpar }\end{array}$ & $\mathrm{G} 2 \mathrm{a}+152$ & $\begin{array}{c}16169 \mathrm{~T}, 16223 \mathrm{~T}, \\
16227 \mathrm{G} 16265 \mathrm{C} \\
16278 \mathrm{~T}\end{array}$ & $\begin{array}{c}73 \mathrm{G}, 146 \mathrm{C}, 152 \mathrm{C}, 263 \mathrm{G} \\
315.1 \mathrm{C}\end{array}$ & female & 1 \\
\hline & & & \multirow{3}{*}{ Aidabol } & R31 & $16362 \mathrm{C}$ & $\begin{array}{c}\text { 73G, } 263 \mathrm{G}, 309.1 \mathrm{C}, \\
315.1 \mathrm{C}\end{array}$ & male & 1 \\
\hline & & & & $\mathrm{C} 4 \mathrm{a} 1 \mathrm{a}+195$ & $\begin{array}{l}\text { 16129A, 16223T, } \\
16298 \mathrm{C}, 16327 \mathrm{~T}\end{array}$ & $\begin{array}{c}73 \mathrm{G}, 195 \mathrm{C}, 248 \mathrm{~A}, 263 \mathrm{G} \\
309.1 \mathrm{C}, 315.1 \mathrm{C}\end{array}$ & male & 1 \\
\hline & & & & $\mathrm{G} 2 \mathrm{a}+152$ & $\begin{array}{c}16169 \mathrm{~T}, 16223 \mathrm{~T}, \\
16227 \mathrm{G}, 16265 \mathrm{C}, \\
16278 \mathrm{~T}\end{array}$ & $\begin{array}{c}73 \mathrm{G}, 146 \mathrm{C}, 152 \mathrm{C}, 263 \mathrm{G} \\
315.1 \mathrm{C}\end{array}$ & male & 1 \\
\hline & & & Kulik & JT & $16126 \mathrm{C}$ & $73 \mathrm{G}, 146 \mathrm{C}, 315.1 \mathrm{C}$ & male & 1 \\
\hline & & $?$ & & C5+16093 & $\begin{array}{c}16093 \mathrm{C}, 16223 \mathrm{~T}, \\
16288 \mathrm{C}, 16298 \mathrm{C}, \\
16327 \mathrm{~T}\end{array}$ & $73 \mathrm{G}, 248 \mathrm{~A}, 263 \mathrm{G}, 315.1 \mathrm{C}$ & male & 1 \\
\hline & & $\begin{array}{l}\text { Orman- } \\
\text { shy }\end{array}$ & & J1d & $\begin{array}{l}16069 \mathrm{~T}, 16126 \mathrm{C}, \\
16153 \mathrm{~A}, 16193 \mathrm{~T}\end{array}$ & $\begin{array}{c}44.1 \mathrm{C}, 73 \mathrm{G}, 146 \mathrm{C}, 152 \mathrm{C} \\
263 \mathrm{G}, 295 \mathrm{~T}, 309.1 \mathrm{C}, \\
315.1 \mathrm{C}\end{array}$ & female & 1 \\
\hline & \multirow{9}{*}{ Karakesek } & Kernei & Daua & $\mathrm{D} 4 \mathrm{t}$ & $\begin{array}{c}\text { 16129A, 16213A, } \\
16223 \mathrm{~T} 16298 \mathrm{C} \\
\end{array}$ & $\begin{array}{c}73 \mathrm{G}, 195 \mathrm{C}, 198 \mathrm{~T}, 247 \mathrm{~d} \\
309.1 \mathrm{C}, 315.1 \mathrm{C} \\
\end{array}$ & male & 1 \\
\hline & & Baibori & & N9a & $\begin{array}{c}16189 \mathrm{C}, 16193.1 \mathrm{C}, \\
16223 \mathrm{~T}, 16257 \mathrm{~A}, \\
16261 \mathrm{~T}\end{array}$ & $\begin{array}{c}73 \mathrm{G}, 150 \mathrm{~T}, 263 \mathrm{G}, 309.1 \mathrm{C} \\
315.1 \mathrm{C}\end{array}$ & female & 1 \\
\hline & & $?$ & & A15 & $\begin{array}{c}16093 \mathrm{C}, 16223 \mathrm{~T}, \\
16290 \mathrm{~T}, 16319 \mathrm{~A}, \\
16362 \mathrm{C} \\
\end{array}$ & $\begin{array}{c}73 \mathrm{G}, 152 \mathrm{C}, 207 \mathrm{~A}, 235 \mathrm{G} \\
309.2 \mathrm{C}, 315.1 \mathrm{C}\end{array}$ & male & 1 \\
\hline & & Aksha & $\begin{array}{l}\text { Boshan- } \\
\text { Moshai- } \\
\text { Koyanshi }\end{array}$ & $\mathrm{D} 4 \mathrm{e} 5 \mathrm{a}$ & $\begin{array}{c}16223 \mathrm{~T}, 16274 \mathrm{~A}, \\
16362 \mathrm{C}\end{array}$ & $\begin{array}{c}73 \mathrm{G}, 152 \mathrm{C}, 263 \mathrm{G}, 309.1 \mathrm{C} \\
315.1 \mathrm{C}\end{array}$ & female & 1 \\
\hline & & Kara & & $\mathrm{H} 2 \mathrm{a} 2 \mathrm{a} 2$ & $\begin{array}{l}16184 \mathrm{G}, 16264 \mathrm{~T}, \\
16295 \mathrm{~T}, 16390 \mathrm{~A}\end{array}$ & $\begin{array}{c}60.1 \mathrm{~T}, 64 \mathrm{~T}, 152 \mathrm{C}, 309.1 \mathrm{C}, \\
309.2 \mathrm{C}, 315.1 \mathrm{C}\end{array}$ & female & 1 \\
\hline & & \multirow{2}{*}{$\begin{array}{l}\text { Bolat- } \\
\text { kozha }\end{array}$} & $\begin{array}{c}\text { Tuiten- } \\
\text { Tanas- } \\
\text { Botei- } \\
\text { Batshor- } \\
\text { Shekshek }\end{array}$ & M10a1a1b & $\begin{array}{c}\text { 16129A, 16193.1T, } \\
16223 \mathrm{~T}, 16311 \mathrm{C}, \\
16357 \mathrm{C}\end{array}$ & $73 \mathrm{G}, 146 \mathrm{C}$ & male & 1 \\
\hline & & & $\begin{array}{c}\text { Tuiten- } \\
\text { Tanas- } \\
\text { Botei- } \\
\text { Batshor- } \\
\text { Shashty } \\
\end{array}$ & $\mathrm{C} 4 \mathrm{a} 2 \mathrm{a} 1$ & $\begin{array}{l}16167 \mathrm{~T}, 16171 \mathrm{G}, \\
16213 \mathrm{~A}, 16223 \mathrm{~T}, \\
16298 \mathrm{C}, 16327 \mathrm{~T}, \\
16344 \mathrm{~T}, 16357 \mathrm{C}\end{array}$ & $\begin{array}{c}47 \mathrm{~A}, 73 \mathrm{G}, 152 \mathrm{C}, 248 \mathrm{~A} \\
263 \mathrm{G}, 309.1 \mathrm{C}, 315.1 \mathrm{C}\end{array}$ & male & 1 \\
\hline & & $?$ & & T1a1'3 & $\begin{array}{l}16126 \mathrm{C}, 16163 \mathrm{G}, \\
16186 \mathrm{~T}, 16189 \mathrm{C}, \\
16192 \mathrm{~T}, 16294 \mathrm{~T}\end{array}$ & $\begin{array}{c}73 \mathrm{G}, 152 \mathrm{C}, 195 \mathrm{C}, 263 \mathrm{G} \\
315.1 \mathrm{C}\end{array}$ & male & 1 \\
\hline & & $?$ & & N9a & $\begin{array}{l}\text { 16189C, 16223T, } \\
16257 \mathrm{~A}, 16261 \mathrm{~T}\end{array}$ & $\begin{array}{c}73 \mathrm{G}, 150 \mathrm{~T}, 263 \mathrm{G}, 309.1 \mathrm{C} \\
315.1 \mathrm{C}\end{array}$ & male & 1 \\
\hline & Begendik & Kozgan & & L3h1a2a & $\begin{array}{c}16093 \mathrm{C}, 16193.1 \mathrm{~T}, \\
16223 \mathrm{~T}, 16311 \mathrm{C}, \\
16357 \mathrm{C}, 16399 \mathrm{G}\end{array}$ & $\begin{array}{c}73 \mathrm{G}, 146 \mathrm{C}, 199 \mathrm{C}, 263 \mathrm{G} \\
309.1 \mathrm{C}, 315.1 \mathrm{C}\end{array}$ & male & 1 \\
\hline & Kuandyk & Karpyk & $\begin{array}{c}\text { Toka- } \\
\text { Kulumbet }\end{array}$ & B4h1 & $\begin{array}{l}\text { 16129A, 16182C, } \\
16183 \mathrm{C}, 16189 \mathrm{C}\end{array}$ & $73 \mathrm{G}, 263 \mathrm{G}, 315.1 \mathrm{C}$ & female & 2 \\
\hline
\end{tabular}


Известия Национальной академии наук Республики Казахстан

\begin{tabular}{|c|c|c|c|c|c|c|c|c|}
\hline & & & & & $16261 \mathrm{~T}$ & & & \\
\hline & & Temesh & & W4 & $\begin{array}{l}16129 \mathrm{~A}, 16223 \mathrm{~T}, \\
16284 \mathrm{G}, 16287 \mathrm{~T}, \\
16304 \mathrm{C}, 16362 \mathrm{C} \\
\end{array}$ & \begin{tabular}{|c|}
$73 \mathrm{G}, 143 \mathrm{~A}, 189 \mathrm{G}, 194 \mathrm{~T}$ \\
195C, 196C, 204C, 207A, \\
263G, 309.1C, 315.1C \\
\end{tabular} & male & 1 \\
\hline & Basentiyin & Syrym & & $\mathrm{X} 2$ & $\begin{array}{c}16182 \mathrm{C}, 16183 \mathrm{C}, \\
16189 \mathrm{C}, 16223 \mathrm{~T}, \\
16278 \mathrm{~T}\end{array}$ & $\begin{array}{c}73 \mathrm{G}, 146 \mathrm{C}, 153 \mathrm{G}, 195 \mathrm{C} \\
263 \mathrm{G}, 309.1 \mathrm{C}, 315.1 \mathrm{C}\end{array}$ & female & 1 \\
\hline & & Karpyk & & HV4b & $16069 \mathrm{~T}$ & $263 \mathrm{G}, 315.1 \mathrm{C}$ & male & 1 \\
\hline \multirow{8}{*}{ Momyn } & \multirow{5}{*}{ Tobykty } & $?$ & & D4ela & $\begin{array}{c}16092 \mathrm{C}, 16111 \mathrm{~T}, \\
16213 \mathrm{~A}, 16223 \mathrm{~T}, \\
16362 \mathrm{C} \\
\end{array}$ & $\begin{array}{c}73 \mathrm{G}, 94 \mathrm{~A}, 146 \mathrm{C}, 263 \mathrm{G} \\
309.1 \mathrm{C}, 315.1 \mathrm{C}\end{array}$ & male & 1 \\
\hline & & \multirow{2}{*}{ Koybas } & \multirow{2}{*}{ Zhaush } & $\mathrm{R} 8$ & $16357 \mathrm{C}$ & $\begin{array}{c}73 \mathrm{G}, 195 \mathrm{C}, 263 \mathrm{G}, 309.1 \mathrm{C} \\
315.1 \mathrm{C} \\
\end{array}$ & female & 1 \\
\hline & & & & G2a2a & $\begin{array}{c}16223 \mathrm{~T}, 16227 \mathrm{G}, \\
16278 \mathrm{~T}\end{array}$ & 195C, 207A, 263G & female & 1 \\
\hline & & \multirow[t]{2}{*}{$\begin{array}{l}\text { Zhuan- } \\
\text { tayak }\end{array}$} & & R7 & $\begin{array}{c}\text { 16189C, 16193.1C, } \\
\text { 162223T, 16261T, } \\
\text { 16319A, 16362C } \\
\end{array}$ & $\begin{array}{c}73 \mathrm{G}, 183 \mathrm{G}, 263 \mathrm{G}, 309.1 \mathrm{C} \\
315.1 \mathrm{C}\end{array}$ & female & 1 \\
\hline & & & & $\mathrm{D} 4 \mathrm{t}$ & $16223 \mathrm{~T}, 16362 \mathrm{C}$ & $73 \mathrm{G}, 309.1 \mathrm{C}, 315.1 \mathrm{C}$ & female & 1 \\
\hline & Atygai & & & D4a6 & $\begin{array}{l}\text { 16093C, 16129A, } \\
16223 \mathrm{~T}, 16362 \mathrm{C}\end{array}$ & $\begin{array}{c}73 \mathrm{G}, 152 \mathrm{C}, 204 \mathrm{C}, 217 \mathrm{C} \\
263 \mathrm{G}, 315.1 \mathrm{C}\end{array}$ & male & 1 \\
\hline & \multirow{2}{*}{ Kanzhigaly } & & & U4b1b1c & $\begin{array}{c}16235 \mathrm{G}, 16311 \mathrm{C}, \\
16356 \mathrm{C}\end{array}$ & $\begin{array}{c}73 \mathrm{G}, 146 \mathrm{C}, 152 \mathrm{C}, 195 \mathrm{C} \\
263 \mathrm{G}, 309.1 \mathrm{C}, 315.1 \mathrm{C}\end{array}$ & male & 1 \\
\hline & & & & U5a2+16294 & $\begin{array}{c}16192 \mathrm{~T}, 16270 \mathrm{~T}, \\
16294 \mathrm{~T}\end{array}$ & $73 \mathrm{G}, 263 \mathrm{G}, 315.1 \mathrm{C}$ & male & 1 \\
\hline Kerei & $?$ & & & N9a & $\begin{array}{c}16223 \mathrm{~T}, 16257 \mathrm{~A}, \\
16261 \mathrm{~T} \\
\end{array}$ & $73 \mathrm{G}, 150 \mathrm{~T}, 263 \mathrm{G}, 315.1 \mathrm{C}$ & female & 1 \\
\hline \multirow[t]{2}{*}{ Ashamaily } & $?$ & & & $\mathrm{D} 4 \mathrm{j} 3$ & $\begin{array}{c}16184 \mathrm{~T}, 16223 \mathrm{~T}, \\
16265 \mathrm{C}, 16311 \mathrm{C}, \\
16362 \mathrm{C} \\
\end{array}$ & $\begin{array}{c}73 \mathrm{G}, 152 \mathrm{C}, 263 \mathrm{G}, 309.1 \mathrm{C}, \\
315.1 \mathrm{C}\end{array}$ & female & 1 \\
\hline & Iteli & $\begin{array}{l}\text { Asha- } \\
\text { maily }\end{array}$ & & $\mathrm{D} 4 \mathrm{o} 2 \mathrm{a}$ & $\begin{array}{l}16093 \mathrm{C} 16223 \mathrm{~T} \\
16232 \mathrm{~T} 16290 \mathrm{~T}\end{array}$ & $\begin{array}{c}73 \mathrm{G} 195 \mathrm{C} 210 \mathrm{G} 263 \mathrm{G} \\
309.1 \mathrm{C} 315.1 \mathrm{C} \\
\end{array}$ & female & 1 \\
\hline$?$ & $\begin{array}{l}\text { Kosai- } \\
\text { batyr }\end{array}$ & & & $\mathrm{D} 4 \mathrm{~s}$ & $\begin{array}{c}16173 \mathrm{~T}, 16223 \mathrm{~T} \\
16362 \mathrm{C}\end{array}$ & $\begin{array}{c}73 \mathrm{G}, 146 \mathrm{C}, 199 \mathrm{C}, 263 \mathrm{G} \\
315.1 \mathrm{C}\end{array}$ & male & 1 \\
\hline$?$ & Zhantekei & Bodes & & W3 & $\begin{array}{c}16093 \mathrm{C}, 16223 \mathrm{~T}, \\
16270 \mathrm{~T}, 16292 \mathrm{~T}, \\
16311 \mathrm{C}\end{array}$ & \begin{tabular}{|c|}
$73 \mathrm{G}, 189 \mathrm{G}, 194 \mathrm{~T}, 195 \mathrm{C}$ \\
196C, 204C, 207A, 263G \\
309.1C, 310C, 315C \\
\end{tabular} & male & 1 \\
\hline \multirow[b]{2}{*}{ Konyrat } & $?$ & & & $\mathrm{D} 4 \mathrm{e} 5 \mathrm{a}$ & $\begin{array}{c}16223 \mathrm{~T}, 16274 \mathrm{~A}, \\
16362 \mathrm{C}\end{array}$ & $\begin{array}{c}73 \mathrm{G}, 152 \mathrm{C}, 263 \mathrm{G}, 309.1 \mathrm{C}, \\
315.1 \mathrm{C}\end{array}$ & male & 1 \\
\hline & Kylshash & & & $\mathrm{U} 2 \mathrm{e} 1 \mathrm{~b}$ & $\begin{array}{c}16051 \mathrm{G}, 16129 \mathrm{C}, \\
16182 \mathrm{~d}, 16183 \mathrm{C}, \\
16189 \mathrm{C}, 16256 \mathrm{~T}, \\
16362 \mathrm{C}\end{array}$ & $\begin{array}{c}73 \mathrm{G}, 152 \mathrm{C}, 200 \mathrm{G}, 217 \mathrm{C} \\
263 \mathrm{G}, 315.1 \mathrm{C}, 340 \mathrm{~T}\end{array}$ & male & 1 \\
\hline Koktinuly & $\begin{array}{l}\text { Kulshy- } \\
\text { gash }\end{array}$ & & & $\mathrm{C} 4 \mathrm{a} 1 \mathrm{a}+195$ & $\begin{array}{c}\text { 16129A 16223T } \\
16298 \mathrm{C}\end{array}$ & $\begin{array}{c}\text { 73G 195C 249d 263G } \\
315.1 \mathrm{C}\end{array}$ & female & 1 \\
\hline Kypshak & $?$ & & & G2a & $\begin{array}{l}16223 \mathrm{~T}, 16227 \mathrm{G}, \\
16278 \mathrm{~T}, 16362 \mathrm{C}\end{array}$ & $73 \mathrm{G}, 263 \mathrm{G}, 315.1 \mathrm{C}$ & female & 1 \\
\hline Zhambai & $?$ & & & $\mathrm{H} 1+16189$ & 16189C, 16193.2C & $263 \mathrm{G}, 309.2 \mathrm{C}, 315.1 \mathrm{C}$ & female & 1 \\
\hline \multirow[t]{4}{*}{ Naiman } & $?$ & & & D4h1 & $\begin{array}{c}16174 \mathrm{~T}, 16223 \mathrm{~T} \\
16362 \mathrm{C}\end{array}$ & $73 \mathrm{G}, 263 \mathrm{G}, 309.1 \mathrm{C}$ & male & 1 \\
\hline & Medet & & & D5 & 16189C 16223T & $\begin{array}{c}\text { 73G 150T 152C 263G } \\
309.1 \mathrm{C} 315 . \mathrm{C}\end{array}$ & female & 1 \\
\hline & Tumatai & & & $\mathrm{T}$ & $16126 \mathrm{C} 16294 \mathrm{~T}$ & $\begin{array}{c}73 \mathrm{G} 152 \mathrm{C} 263 \mathrm{G} 309.1 \mathrm{C} \\
315.1 \mathrm{C}\end{array}$ & female & 1 \\
\hline & $?$ & & & $\mathrm{C} 4 \mathrm{a} 1+195$ & $\begin{array}{l}16093 \mathrm{C} 16129 \mathrm{~A} \\
16223 \mathrm{~T} 16298 \mathrm{C}\end{array}$ & $\begin{array}{c}73 \mathrm{G} 195 \mathrm{C} 247 \mathrm{~d} 263 \mathrm{G} \\
315.1 \mathrm{C}\end{array}$ & female & 1 \\
\hline Okiresh & Belgibai & Suinshi & $\begin{array}{c}\text { Tolegetai } \\
\text { baba- } \\
\text { Kytai bi- } \\
\text { Karakerei }\end{array}$ & $\mathrm{A} 5 \mathrm{a}$ & $\begin{array}{l}16187 \mathrm{~T}, 16223 \mathrm{~T}, \\
16290 \mathrm{~T}, 16319 \mathrm{~A}\end{array}$ & $\begin{array}{c}73 \mathrm{G}, 150 \mathrm{~T}, 235 \mathrm{G}, 263 \mathrm{G} \\
309.1 \mathrm{C}, 315.1 \mathrm{C}\end{array}$ & female & 1 \\
\hline Tolegetai & Matai & Togyz & & $Z+152$ & $\begin{array}{c}16185 \mathrm{~T}, 16189 . \operatorname{Del}(\mathrm{T}) \\
16223 \mathrm{~T}, 16260 \mathrm{~T}\end{array}$ & $\begin{array}{c}\text { 73G, 152C, 246T, } \\
\text { 247.Del(-G), 263G, }\end{array}$ & female & 1 \\
\hline
\end{tabular}




\begin{tabular}{|c|c|c|c|c|c|c|c|c|}
\hline & & & & & $16288 \mathrm{C}, 16298 \mathrm{C}$ & $309.1 \mathrm{C}, 315.1 \mathrm{C}$ & & \\
\hline \multirow[t]{3}{*}{ Uak } & $?$ & & & D5 & $16189 \mathrm{C} 16223 \mathrm{~T}$ & $\begin{array}{c}\text { 73G 150T 152C 263G } \\
309.1 \mathrm{C} 315 . \mathrm{C} \\
\end{array}$ & female & 1 \\
\hline & $?$ & & & G2a & $\begin{array}{l}16223 \mathrm{~T}, 16227 \mathrm{G} \\
16278 \mathrm{~T}, 16362 \mathrm{C}\end{array}$ & $73 \mathrm{G}, 152 \mathrm{C}, 263 \mathrm{G}, 315.1 \mathrm{C}$ & male & 1 \\
\hline & $?$ & & & $\mathrm{D} 4 \mathrm{j} 2$ & $\begin{array}{c}16223 \mathrm{~T}, 16291 \mathrm{~T}, \\
16362 \mathrm{C}\end{array}$ & $73 \mathrm{G}, 263 \mathrm{G}, 315.1 \mathrm{C}$ & female & 1 \\
\hline \multicolumn{9}{|l|}{ Kishi zhuz } \\
\hline \multicolumn{9}{|l|}{ Baiuly } \\
\hline \multirow[t]{2}{*}{ Adai } & Tazike & Kabakai & Alke & $\mathrm{D} 4 \mathrm{t}$ & $\begin{array}{l}\text { 16129A 16213A } \\
16223 \mathrm{~T} 16298 \mathrm{C}\end{array}$ & $\begin{array}{c}\text { 73G 195C 198T 247d } \\
309.1 \mathrm{C} 315.1 \mathrm{C}\end{array}$ & female & 1 \\
\hline & $?$ & & & I1 & $\begin{array}{l}\text { 16129A, 16223T, } \\
\text { 16311C, 16391A }\end{array}$ & $\begin{array}{c}73 \mathrm{G}, 199 \mathrm{C}, 204 \mathrm{C}, 250 \mathrm{C} \\
263 \mathrm{G}, 309.1 \mathrm{C}, 315.1 \mathrm{C}\end{array}$ & male & 1 \\
\hline Salik & $?$ & & & $\mathrm{C} 4 \mathrm{a} 2 \mathrm{a} 1$ & $\begin{array}{c}16167 \mathrm{~T}, 16171 \mathrm{G}, \\
16223 \mathrm{~T}, 16298 \mathrm{C}, \\
16327 \mathrm{~T}, 16344 \mathrm{~T} \\
16357 \mathrm{C}\end{array}$ & $\begin{array}{c}47 \mathrm{~A}, 73 \mathrm{G}, 249 \mathrm{~d}, 263 \mathrm{G} \\
309.1 \mathrm{C}, 315.1 \mathrm{C}\end{array}$ & male & 1 \\
\hline \multicolumn{9}{|l|}{ Alimuly } \\
\hline $\begin{array}{l}\text { Kete } \\
\text { (Ak-kete) }\end{array}$ & $?$ & & & $\mathrm{H} 1 \mathrm{~b}$ & $\begin{array}{c}16189 \mathrm{C}, 16193.1 \mathrm{C}, \\
16356 \mathrm{C}, 16363 \mathrm{C}\end{array}$ & $249 \mathrm{G}, 263 \mathrm{G}, 315.1 \mathrm{C}$ & male & 1 \\
\hline Shomekei & $\begin{array}{l}\text { Kozha- } \\
\text { keldi }\end{array}$ & & & H1ao & $16278 \mathrm{~T}$ & $\begin{array}{c}93 \mathrm{G}, 143 \mathrm{~A}, 263 \mathrm{G}, \\
308.1 \mathrm{CT}, 315.1 \mathrm{C}\end{array}$ & female & 1 \\
\hline Tortkara & $?$ & & & $\mid \begin{array}{c}A+152+1636 \\
2\end{array}$ & $\begin{array}{l}16086 \mathrm{C}, 16223 \mathrm{~T}, \\
16256 \mathrm{~T}, 16290 \mathrm{~T}, \\
16319 \mathrm{~A}, 16362 \mathrm{C}\end{array}$ & $\begin{array}{c}73 \mathrm{G}, 152 \mathrm{C}, 235 \mathrm{G}, 263 \mathrm{G} \\
309.1 \mathrm{C}, 315.1 \mathrm{C}\end{array}$ & male & 1 \\
\hline \multicolumn{9}{|l|}{ Zhetiru } \\
\hline Zhagalbaily & $?$ & & & $\begin{array}{c}\mathrm{H} 2 \mathrm{a}+152+16 \\
311\end{array}$ & $16311 \mathrm{C}, 16324 \mathrm{C}$ & $\begin{array}{c}152 \mathrm{C}, 207 \mathrm{~A}, 263 \mathrm{G}, \\
309.1 \mathrm{C}, 315.1 \mathrm{C}\end{array}$ & male & 1 \\
\hline \multirow[b]{2}{*}{ Tama } & $?$ & & & $\mathrm{H} 1 \mathrm{e} 2 \mathrm{c}$ & - & $\begin{array}{c}73 \mathrm{G}, 263 \mathrm{G}, 309.1 \mathrm{C}, \\
315.1 \mathrm{C} \\
\end{array}$ & male & 1 \\
\hline & $?$ & & & $\mathrm{~J} 2 \mathrm{~b} 1 \mathrm{c} 1$ & $\begin{array}{l}16069 \mathrm{~T}, 16126 \mathrm{C}, \\
16148 \mathrm{~T}, 16193 \mathrm{~T}, \\
16261 \mathrm{~T}, 16301 \mathrm{~T}, \\
16311 \mathrm{C}, 16319 \mathrm{~A}, \\
16355 \mathrm{~T}, 16356 \mathrm{C}, \\
16362 \mathrm{C}, 16368 \mathrm{C}, \\
16390 \mathrm{~A}, 16399 \mathrm{G}\end{array}$ & $\begin{array}{c}73 \mathrm{G}, 150 \mathrm{~T}, 152 \mathrm{C}, 263 \mathrm{G} \\
315.1 \mathrm{C}\end{array}$ & male & 1 \\
\hline \multirow[b]{2}{*}{ Tabyn } & $?$ & & & $\mathrm{D} 4 \mathrm{t}$ & $16223 \mathrm{~T}, 16362 \mathrm{C}$ & $73 \mathrm{G}, 194 \mathrm{~T}, 279 \mathrm{G}, 315.1 \mathrm{C}$ & male & 1 \\
\hline & $?$ & & & $\begin{array}{c}\text { E1a2+(16261 } \\
)\end{array}$ & $\begin{array}{l}16147 \mathrm{~A}, 16172 \mathrm{C}, \\
16189 \mathrm{C}, 16223 \mathrm{~T}, \\
16261 \mathrm{~T}, 16301 \mathrm{~T}, \\
16311 \mathrm{C}, 16319 \mathrm{~A}, \\
16355 \mathrm{~T}, 16356 \mathrm{C}, \\
16362 \mathrm{C}, 16368 \mathrm{C}, \\
16390 \mathrm{~A}, 16399 \mathrm{G}\end{array}$ & $\begin{array}{c}63 \mathrm{C}, 73 \mathrm{G}, 152 \mathrm{C}, 199 \mathrm{C} \\
204 \mathrm{C}, 263 \mathrm{G}, 315.1 \mathrm{C}\end{array}$ & male & 1 \\
\hline \multicolumn{9}{|c|}{ Non belong to any zhuz } \\
\hline \multirow[t]{2}{*}{ Tore } & $?$ & & & & & & & \\
\hline & $?$ & & & D4e1a1 & $16223 \mathrm{~T}, 16362 \mathrm{C}$ & $73 \mathrm{G}, 94 \mathrm{~A}, 263 \mathrm{G}, 315.1 \mathrm{C}$ & male & 1 \\
\hline Zhadik auleity & $?$ & & & U1a3 & $\begin{array}{l}\text { 16182d, 16183C, } \\
16189 \mathrm{C}, 16249 \mathrm{C}\end{array}$ & $\begin{array}{c}73 \mathrm{G}, 146 \mathrm{C}, 263 \mathrm{G}, 285 \mathrm{~T} \\
309.1 \mathrm{C}, 315.1 \mathrm{C} \\
\end{array}$ & male & 1 \\
\hline \multirow[t]{2}{*}{ Kozha } & $?$ & & & $\mathrm{R} 2$ & $\begin{array}{c}16037 \mathrm{G}, 16071 \mathrm{~T}, \\
16172 \mathrm{C}\end{array}$ & $\begin{array}{c}73 \mathrm{G}, 152 \mathrm{C}, 263 \mathrm{G}, 309.1 \mathrm{C}, \\
315.1 \mathrm{C}\end{array}$ & female & 1 \\
\hline & Aksuiek & & & $\mathrm{B} 2 \mathrm{o}$ & $\begin{array}{c}16092 \mathrm{C} 16182 \mathrm{C} \\
16183 \mathrm{C} 16189 \mathrm{C} \\
16217 \mathrm{C} \\
\end{array}$ & 73G 263G 315.1C & female & 1 \\
\hline $\begin{array}{l}\text { Kereyit } \\
\text { kozha }\end{array}$ & $?$ & & & C4a1a4a & $\begin{array}{l}16129 \mathrm{~A}, 16150 \mathrm{~T}, \\
16223 \mathrm{~T}, 16298 \mathrm{C}, \\
16301 \mathrm{~T}, 16311 \mathrm{C}, \\
16327 \mathrm{~T}, 16355 \mathrm{~T}, \\
16356 \mathrm{C}, 16368 \mathrm{C},\end{array}$ & $\begin{array}{c}73 \mathrm{G}, 195 \mathrm{C}, 248 \mathrm{~d}, 263 \mathrm{G} \\
315.1 \mathrm{C}\end{array}$ & female & 1 \\
\hline
\end{tabular}


Известия Национальной академии наук Республики Казахстан

\begin{tabular}{|c|c|c|c|c|c|c|}
\hline & & & 16390A, 16399G & & & \\
\hline Seyit & $?$ & H1e1a4 & $16311 \mathrm{C}$ & $\begin{array}{c}263 \mathrm{G}, 309.1 \mathrm{C}, 309.2 \mathrm{C} \\
315.1 \mathrm{C} \\
\end{array}$ & female & 1 \\
\hline Sunak & $?$ & $\mathrm{H} 2 \mathrm{a} 2 \mathrm{a}$ & - & $263 \mathrm{G}, 315.1 \mathrm{C}$ & male & 1 \\
\hline \multirow[t]{2}{*}{$\begin{array}{l}\text { Nogai- } \\
\text { kazakh }\end{array}$} & $?$ & N9a2'4'5'11 & $\begin{array}{l}16166 \mathrm{G}, 16172 \mathrm{C}, \\
16223 \mathrm{~T}, 16257 \mathrm{~A}, \\
16261 \mathrm{~T}, 16304 \mathrm{C}\end{array}$ & $\begin{array}{c}73 \mathrm{G}, 150 \mathrm{~T}, 263 \mathrm{G}, 309.1 \mathrm{C} \\
315.1 \mathrm{C}\end{array}$ & male & 1 \\
\hline & $?$ & U4 & $16356 \mathrm{C}$ & $\begin{array}{c}73 \mathrm{G}, 195 \mathrm{C}, 263 \mathrm{G}, 309.1 \mathrm{C} \\
315.1 \mathrm{C}\end{array}$ & male & 1 \\
\hline
\end{tabular}

Corresponding to the Cambridge Reference Sequence (CRS) [12, 13], with which all other Human mtDNAs were compared, the D haplogroup was originated from haplogroup HVR D haplogroup has an East Asian origin [14]. It is believed, that mtDNA D haplogroup appeared in Asia 48000 B.C. [15]. The subclade D4 are the principle branch of D. D4 is the most common mtDNA haplogroup among modern populations of northern East Asia, such as Japanese, Okinawans, Koreans, and Mongolic- or Tungusicspeaking populations of northern China $[7,16]$. D4 is also the most frequently occurring haplogroup among the Buryats, Khamnigans, Kalmyks, and the Telenghits and Kazakhs of the Altai region [7, 17]. D4 mtDNA branch spread also all over China, Southeast Asia, Siberia, Central Asia, and indigenous peoples of the Americas [18, 19].

$\mathrm{H}$ haplogroup is believed to have arisen in eastern Europe or western Asia [20]. There is an opinion, that origin of $\mathrm{H}$ clade is associated with Southwest Asia [21], around 20000 to 25000 years ago. Nowaday, the mtDNA haplogroup $\mathrm{H}$ is predominantly found in Europe, and is believed to have evolved before the Last Glacial Maximum (LGM). Firstly it expanded in the northern Near East and Southern Caucasus between 33000 and 26000 years ago. Later migrations from Iberia allows to suggest, that the clade reached Europe before the LGM. mtDNA H haplogroup has also spread to parts of Africa, Siberia and inner Asia. Today, around $40 \%$ of all maternal lineages in Europe belong to haplogroup $\mathrm{H}$.

It is believed, that mtDNA C haplogroup to have originated somewhere between the Caspian Sea and Lake Baikal some 24000 years B.C. Haplogroup C is spread in Northeast Asia [7], including Siberia. Rissian scientists showed, that, in Eurasia, mtDNA C haplogroup was most frequent among populations of arctic Siberia, such as Yukaghirs and Nganasans [19]. At indigenous peoples of the Americas, the haplogroup $\mathrm{C}$ (with subclades $\mathrm{C} 1 \mathrm{~b}, \mathrm{C} 1 \mathrm{c}, \mathrm{C} 1 \mathrm{~d}$, and $\mathrm{C} 4 \mathrm{c}$ ) is one of five mtDNA haplogroups, the others are $\mathrm{A}, \mathrm{B}, \mathrm{D}$, and $\mathrm{X}$ haplogroups [22]. The subclade $\mathrm{C} 1 \mathrm{a}$ is found only in population of Asia.

For most mtDNA haplotypes, regional and racial specificity have been established. For an example, in the gene pools of the peoples of Europe and Western Asia, there are mainly 10 major mtDNA haplotypes (HVR *, H, V, J, T, U, K, I, W, X). In the gene pools of Mongoloid populations of Eastern, Central and Nothern Asia another 10 mtDNA haplogroups found (A, B, C, D, E, F, G, Y, Z, M *), and in Negroids - mtDNA of macro group L [2, 4, 7, 23].

Known data about modern Kazakh mtDNA types are contradictory, which may be due to the insufficient amount of collected genetic material for reliable generalization. According to the studies of two different research groups [2, 4], 31.7-45\% of mitochondrial haplotypes of the Kazakh ethnos have an "West Eurasian" origin, 50-63.4\% have an "Eastern Eurasian" origin, and 0-4.9\% are characteristic of the population of India. We should note that in the work of D. Comas and others [2] mtDNA haplotypes of 232 individuals from 12 populations were investigated, among others only 20 were Kazakhs, which is an unrepresentative sample for any conclusions.

More representative population of modern Kazakh (246 individuals with different geographical localization) has been studied by Berezina G.M. with co-authors [3]. According to the results, 58\% of Kazakh mtDNAs were haplogroup D (17.9\%), C (16\%), G (16\%), A (3.25\%), F (2.44\%), presumably Eastern Eurasian. And 41.46\% were haplogroups H (13\%), T (4.07\%), J (4.07\%), K (4.07\%), U5 (3.25\%), I $(0.41 \%), \mathrm{V}(0.81 \%), \mathrm{W}(1.63 \%)$, presumably of Western Eurasian origin.

In general, in the studied cohort of modern Kazakh, the presence of typically "Asian" mtDNA haplotypes (A5a, A15, A+152+16362, B2o, B4h1, C4, C4a1a+195, C4a1a2, C4a1a4a, C4a2a1, C4b1, C5a, C5+16093, D4a6, D4b2d, D4e1a, D4e1a1, D4e5a, D4j2, D4j3, D4s, D4t, D4+195, D4o2a, D5, E1a2 +16261, F, G2a, G2a+152, G2a2, G2a5, Z+152(M8), M6, M10a1a1b) is estimated as 50\%, "European" (H1+16189, H1ao, H1b, H1e1a4, H1e2c, H1e-16129, H2a+152+16311, H2a2a, H2a2a2, H7a1, H13a1d, 
HV4b, I1, I1a, J1c16, J1d, J2b1c1, JT, K1c, T1a1, T1a1'3, T2, T, T2b11, U1a3, U1b2, U2e1h, U2e1b, U2e1'2'3', U3a3, U4, U4b1b1c, U5a2+1629, X2, W3, W4) - 38.54\%; and ancient groups traced from "Middle East", but originated in Central and South-East Asia (N1a, N1a3a, N1b, N9a N9a1'3, N9a2'4'5'11, R2, R7, R8) - 7.29\%; there is even 1 person with an ancient "African" group - L3h1a2a $(1.04 \%)$.

The presence of such a variety of maternal lines for a small cohort of representatives of the same tribe testifies the Kazakh history full of migrations. That's why we should to mention the malestones in Kazakh ethnic history.

Ethnic history of the Kazakh people is rooted in the ancient period of settling the territory of modern Kazakhstan. The first archaeological finds in the territory of Kazakhstan belong to the Paleolithic period. According to archaeological and paleoanthropological data, the ancient tribes spread on the territory of Kazakhstan since the Bronze Age. During the Bronze Age the ancient population of Kazakhstan was concentrated at the center of a large ethno-cultural region of Eurasia and was one of the representatives of extensive anthropological formation of steppe type proto-European trunk [1]. Nomadic animal husbandry becomes the predominant type of activity to the I millennium BC. The irrigated agriculture, the production of iron and metal manufacture have been developed. Stratification occurred among the nomads, the tribal leaders were indicated, new association of tribes and tribal units appeared, among which the most widely known was Saka Union of tribes. During this period, Savromats tribes settled in western Kazakhstan. At the end of I millennium BC in Kazakhstan there are new tribes: Usuns (from Balkhash to Issyk-Kul lakes), Kangyuy (foothills of Karatau mountains and Syrdarya river basin), Alans (between Aral and Caspian seas).

The statehood on the territory of Kazakhstan established in the I millennium AD. There were areas of sedentary culture: Turk Kaganat (VI cent.), Turgesh and Karluk kaganats (VIII cent.). At the same period the great migration of tribes began from the Altai, southern Siberia and Central Asia to the territory of present-day Kazakhstan and further to the west. The Hun period of "Great Migration" is dated by IVVII centuries. However, the large-scale movement of the Hun tribes, which led to significant changes in the ethnic and political map of Eurasia, began in I-II centuries. The Huns ancestors - Turkic people "hunnu" lived in the territory of modern Mongolia, Buryatia, and North China.

In X-XI centuries a significant territory of Semirechye was a part of Karakhanid State. Nomadic tribes from south-west and western Kazakhstan entered into an Union of Oguz tribes. In the north-eastern Kazakhstan territory tribal Union of Kimaks was formed. The vast territory of Central Kazakhstan became known as the Kipchaks country or Dasht-i-Kipchak. Start of the XIII century marked by the Mongol invasion and the establishment of the Mongol districts (ulus - Mongolian) in the territory of Kazakhstan. The first Kazakh Khanate (XV-XVI centuries, Semirechye) was a tribal union and included the tribes Uisuns, Kangly, Dulats, Zhalair, Naimans, Argyns and others. These tribes formed a single ethnic array.

Interesting data on paleo-mtDNAs have been presented by C. Lalueza-Fox with co-authors [4]. They studied human teeth 36 of 15 graves located in Kazakhstan, radiocarbon dates vary from XIV-XI centuries BC to the III-V centuries BC. The 21 teeth revealed Caucasoid (Western Eurasian) mtDNA haplotypes, and 6 teeth - the Eastern Eurasian. The authors noticed the dynamics of changes in the haplogroups of the ancient population of Kazakhstan in the direction to the East Eurasia.

Territorially all Kazakh tribes were divided into three major groups ("Zhuzes"): Elder Zhuz (Uly zhuz, 12 tribes), Middle Zhuz (Orta zhuz, 6 tribes), and Junior Zhuz (Kishi zhuz, 3 tribes). Elder Zhuz tribes were mostly occupied South and South-East Kazakhstan, the Middle Zhuz tribes lived in Eastern, Northern and Central Kazakhstan, and the Junior Zhuz tribes traditionally lived in Western Kazakhstan. Also, there are 5 (or 7) tribes which not included to any zhuz.

Obtained data revealed that the modern descendants of ancient Kazakh tribes demonstrate a high degree of heterogeneity in relation to the maternal lines. Because the our studied cohort represents the vast variety of mtDNA haplogroups reflecting the history of ancient nomadic tribes migration we have tried to look after genetic distances between representatives of different tribes combining the data fo tribes unions - Zhuzes.

For this analyses we took into account the mutations in total number of 135 loci in HVR1 and HVR2 regions of mtDNA. Genetic heterogeneity of each locus and cohort (Table 1), the genetic distances and identity (Nei) were calculated in the program GenAlEx 6.2 (table 2). 
Известия Национальной академии наук Республики Казахстан

Table 1 - The heterogeneity characteristics of studied cohorts on HVR1 and HVR2 mtDNA loci

\begin{tabular}{|l|c|c|c|c|c|c|c|c|}
\hline \multicolumn{1}{|c|}{ Indexes* } & $\mathrm{N}$ & $\mathrm{Na}$ & $\mathrm{Ne}$ & $\mathrm{I}$ & $\mathrm{h}$ & \multicolumn{2}{c|}{ uh } & $\begin{array}{c}\text { Polymorphic } \\
\text { Loci, \% }\end{array}$ \\
\hline Cohort & \multicolumn{7}{|c|}{ Grand Mean and SE over Loci for each Cohorts } \\
\hline Uly zhuz & $19,000 \pm 0$ & $0,889 \pm 0,085$ & $1,104 \pm 0,016$ & $0,132 \pm 0,015$ & $0,075 \pm 0,010$ & $0,080 \pm 0,010$ & $43,70 \%$ \\
\hline Orta zhuz & $55,000 \pm 0$ & $1,541 \pm 0,073$ & $1,097 \pm 0,014$ & $0,144 \pm 0,012$ & $0,075 \pm 0,008$ & $0,076 \pm 0,008$ & $77,04 \%$ \\
\hline Kishi zhuz & $11,000 \pm 0$ & $0,837 \pm 0,085$ & $1,142 \pm 0,019$ & $0,164 \pm 0,018$ & $0,099 \pm 0,012$ & $0,109 \pm 0,013$ & $41,48 \%$ \\
\hline Non zhuz & $9,000 \pm 0$ & $0,533 \pm 0,076$ & $1,090 \pm 0,015$ & $0,106 \pm 0,016$ & $0,064 \pm 0,010$ & $0,072 \pm 0,011$ & $25,93 \%$ \\
\hline & \multicolumn{7}{|c|}{ Grand Mean and SE over Loci } \\
\hline Total Cohort & $23,500 \pm 0,80$ & $0,950 \pm 0,043$ & $1,108 \pm 0,008$ & $0,136 \pm 0,008$ & $0,078 \pm 0,005$ & $0,084 \pm 0,005$ & $47,04 \pm 10,75$ \\
\hline
\end{tabular}

*Na - number of different alleles; Ne - number of effective alleles; I - Shannon's information index; $\mathrm{h}$ - diversity; uh - unbiased Diversity.

Table 2 - Nei Genetic distance and identity between representatives of modern Kazakh based on mutations of variable regions (HVR1 and HVR2) of mtDNA

\begin{tabular}{|c|c|c|c|c|}
\hline \multicolumn{5}{|c|}{ Pairwise Population Matrix of Nei Genetic Distance // Identity } \\
\hline $0,000 / / 1,000$ & & & & Uly zhuz \\
\hline $0,003 / / 0,997$ & $0,000 / / 1,000$ & & & Orta zhuz \\
\hline $0,009 / / 0,991$ & $0,006 / / 0,994$ & $0,000 / / 1,000$ & & Non zhuz zhuz \\
\hline $0,006 / / 0,994$ & $0,006 / / 0,994$ & $0,008 / / 0,992$ & $0,000 / / 1,000$ & Non huz \\
\hline Uly zhuz & Orta zhuz & Kishi zhuz & & \\
\hline
\end{tabular}

Evolutionary connections were defined by the Neighbor-Joining method [24]. The phylogenetic tree was inferred using the UPGMA method and constructed in the MEGA7 program [25]. The figure 3 presents obtained phylogenetic tree. The optimal tree with the sum of branch length $=0.01216667$ is shown.
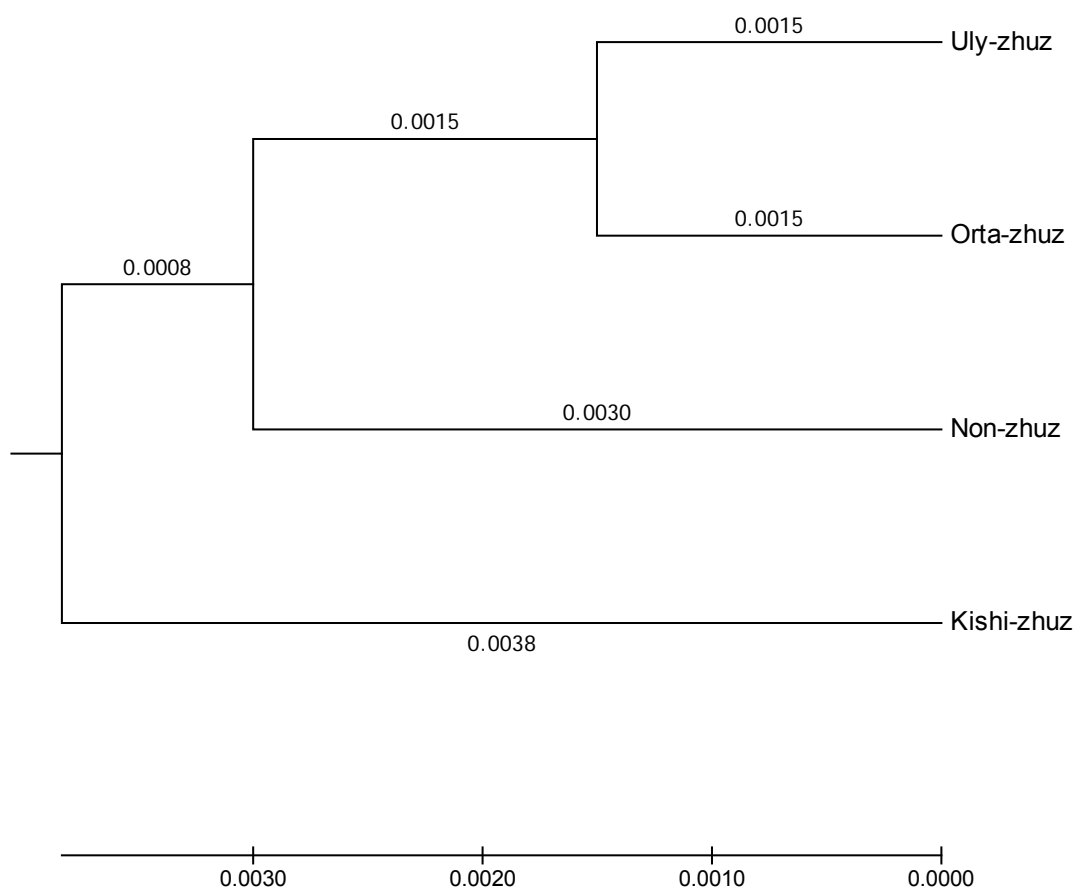

Figure 3 - Evolution relationships of modern Kazakh 
The presented data show that the maternal lines of representatives of different zhuzes are characterized by genetic proximity despite of great genetic diversity. The Kishi zhuz maternal lines are more distant from representatives of other tribe unions $(\mathrm{GD}=0,0038)$. We suggest that this is due to the lower migration activity of the population of Western Kazakhstan in comparison with other regions of the Republic.

Thus, the analysis of mitochondrial DNA of modern Kazakhs with a wide geographic localization and tribal affiliation shows that the Kazakh's maternal lines are characterized by great diversity of mtDNA haplogroups, reflecting the historical migration of the population of Eurasia with the predominance of "Asian" and "European" components. The analysis of mutations of hypervariable regions of mtDNA regarding Zhuz-affiliation determines the genetic affinity of all Kazakh maternal lines.

\section{REFERENCES}

[1] Ismagulov O., Ismagulova A.O. (2004) The most ancient inhabitants of Kazakhstan: the view of an anthropologist [Drevneishie nasel'niki Kazakhstana: vzgliad antropologa] // World discovery Kazakhstan 17: 38-42. (In Russ.).

[2] Comas D., Calafell F., Mateu E., Perez-Lezaun A., Bosch E., Martinez-Arias R. et al. (1998) Trading genes along the silk road: mtDNA sequences and the origin of central Asian populations // Am. J. Hum. Genet, 63: 1824-1838. DOI 10.1086/302133.

[3] Berezina G.M., Svyatova G.S., Makhmutova Zh. (2011) The analysis of the genetic structure of the Kazakh population as estimated from mitochondrial DNA polymorphism // Medical and Health Science Journal (MHSJ), 6: 2-6.

[4] Lalueza-Fox C., Sampietro M.L., Gilbert M.T., Castri L., Facchini F., Pettener D. et al. (2004) Unravelling migrations in the steppe: mitochondrial DNA sequences from ancient central Asians // Proc Biol Sci, 271: 941-947. DOI 10.1098/rspb.2004.2698.

[5] Yao Y.G., Kong Q.P., Wang C.Y., Zhu C.L., Zhang Y.P. (2004) Different Matrilineal Contributions to Genetic Structure of Ethnic Groups in the Silk Road Region in China // Molecular Biology and Evolution, 21(12): 2265-2280. DOI 10.1093/molbev/msh238.

[6] Bennet C., Kaestle F. (2010) Investigation of Ancient DNA from Western Siberia and the Sargat Culture // Human Biology, 82(2): 143-156. doi.org/10.3378/027.082.0202.

[7] Derenko M.V., Malyarchuk B.A., Denisova G.A., Perkova M.A., Rogalla U., Grzybowski T., Khusnutdinova E.K., Dambueva I., Zakharov I. (2012) Complete Mitochondrial DNA Analysis of Eastern Eurasian Haplogroups Rarely Found in Populations of Northern Asia and Eastern Europe, PLoS One, 7(2): e32179. DOI 10.1371/journal.pone.0032179.

[8] Derenko M.V., Maliarchuk B.A. (2010) Molecular phylogeography of the population of northern Eurasia according to the data on the variability of mitochondrial DNA [Molekuliarnaia filogeografiia naseleniia severnoi Evrazii po dannym ob izmenchivosti mitokhondrial'noi DNK] / executive editor A. Zakharov-Gezekhus [otv. red. I.A. Zakharov-Gezekhus], Magadan: SVNTs DVO RAN. (In Russ.).

[9] Berezina G.M., Sviatova G.S., Abdullaeva A.I., Bermisheva M., Kutuev I., Khusnutdinova E.K., Billerns R. (2005) Polymorphism of mitochondrial DNA in the Kazakh population [Polimorfizm mitokhondrial'noi DNK v kazakhskoi populiatsii] // Medical Genetics [Meditsinskaia genetika], 4(3): 108-113. (In Russ.).

[10] Dulik M.C., Osipova L.P., Schurr T.G. (2011) Y-Chromosome Variation in Altaian Kazakhs Reveals a Common Paternal Gene Pool for Kazakhs and the Influence of Mongolian Expansions, PLoS One, http://dx.doi.org/10.1371/journal.pone.0017548.

[11] Tarlykov P.V., Zholdybayeva E.V., Akilzhanova A.R., Nurkina Zh.M., Sabitov Zh.M., Rahypbekov T.K., Ramanculov E.M. (2013) Mitochondrial and Y-chromosomal profile of the Kazakh population from East Kazakhstan // Croatian Medical Journal, 54: 17-24. DOI 10.3325/cmj.2013.54.17.

[12] Homo sapiens mitochondrion, complete genome. "Revised Cambridge Reference Sequence (rCRS): accession NC_012920" // National Center for Biotechnology Information. Retrieve done 30 January 2016.

[13] Hwan Young Lee, Injee Song, Eunho Ha, Sung-Bae Cho, Woo Ick Yang and Kyoung-Jin Shin (2008) mtDNAmanager: a Web-based tool for the management and quality analysis of mitochondrial DNA control-region sequences // BMC Bioinformatics, 9(483). Doi 10.1186/1471-2105-9-483.

[14] Kong Q.P., Yao Y.G., Sun C., Bandelt H.J., Zhu C.L., et al. (2003) Phylogeny of East Asian mitochondrial DNA liner ages inferred from complete sequences // Am J Hum Genet, 73: 671-676.

[15] Soares P., Ermini L., Thomson N., Mormina M., Rito T., Röhl A., Salas A., Oppenheimer S., Macaulay V., Richards M. (2009) Correcting for purifying selection: an improved human mitochondrial molecular clock // Am J Hum Genet, 84(6): 74059. DOI 10.1016/j.ajhg.2009.05.001.

[16] Maruyama S., Minaguchi K., Saitou N. (2003) Sequence polymorphisms of the mitochondrial DNA control region and phylogenetic analysis of mtDNA lineages in the Japanese population // Int J Legal Med, 117: 218-225. DOI 10.1007/s00414-003-0379-2.

[17] Derenko M., Malyarchuk B., Grzybowski T. et al. (2007) Phylogeographic Analysis of Mitochondrial DNA in Northern Asian Populations // Am J Hum Genet, 81: 1025-1041. DOI 10.1086/522933.

[18] Malhi R.S., Breece K.E., Schultz S., Beth A., Kaestle F.A. (2004) Patterns of mtDNA Diversity in Northwestern North America // Human Biology, 76(1): 33-54. DOI 10.1353/hub.2004.0023.

[19] Volodko N.V., Starikovskaya E.B., Mazunin I.O. et al. (2008) Mitochondrial Genome Diversity in Arctic Siberians, with Particular Reference to the Evolutionary History of Beringia and Pleistocenic Peopling of the Americas // The American Journal of Human Genetics, 82: 1084-1100. DOI 10.1016/j.ajhg.2008.03.019.

[20] Pereira L., Richards M., Goios A., Alonso A., Albarrán C., Garcia O., Behar D.M., Gölge M., Hatina J., Al-Gazali L., Bradley D.G., Macaulay V., Amorim A. (2005) High-resolution mtDNA evidence for the late-glacial resettlement of Europe from an Iberian refugium // Genome Res, 15: 19-24. DOI 10.1101/gr.3182305. 
[21] Achilli A., Rengo C., Magri C. et al. (2004) The Molecular Dissection of mtDNA Haplogroup H Confirms That the Franco-Cantabrian Glacial Refuge Was a Major Source for the European Gene Pool // American Journal of Human Genetics, 75(5): 910-8. DOI 10.1086/425590.

[22] Söchtig J., Álvarez-Iglesias V., Mosquera-Miguel A., Gelabert-Besada M., Gómez-Carballa A., Salas A. (2015) Genomic insights on the ethno-history of the Maya and the "Ladinos" from Guatemala // BMC Genomics, 16(1): 131. DOI 10.1186/s12864-015-1339-1.

[23] Comas D., Plaza S., Wells R.S., Yuldaseva N., Lao O., Calafell F., Bertranpetit J. (2004) Admixture, migrations, and dispersals in Central Asia: evidence from maternal DNA lineages // European Journal of Human Genetics, 12(6): 495-504. DOI 10.1038/sj.ejhg.5201160.

[24] Saitou N., Nei M. (1987) The neighbor-joining method: A new method for reconstructing phylogenetic trees // Molecular Biology and Evolution, 4: 406-425. doi.org/10.1093/oxfordjournals.molbev.a040454.

[25] Kumar S., Stecher G., Tamura K. (2016) MEGA7: Molecular Evolutionary Genetics Analysis version 7.0 for bigger datasets // Molecular Biology and Evolution, 33: 1870-1874. DOI 10.1093/molbev/msw054.

\section{Л. Б. Жансүгірова, Г. С. Жунусова, Нұржибек, С. А. Әбдікерім, А. С. Әмірғалиева, Б. О. Бекманов, Э. М. Хусаинова}

Популяциялық генетика зертханасы, РМК «Жалпы генетика және цитология институты» ҚР БҒМ ҒҚ, Алматы, Қазақстан

\section{ЭТНИКАЛЫҚ ҚАЗАҚТАРДЫН мТДНК БАҚЫЛАУ АЙМАҚТАРДЫҢ ТАЛДАУЫ}

Аннотация. Географиялық орналасуына және руына қарай қазіргі заманғы қазақтардың митохондриялық ДНҚ-на жасалған талдау барлық аналар линияларының "азиялық" және "европалық" топтарына қатысты Евразия халықтарының тарихи қоныс аударуын көрсететін мтДНҚ гаплотоптарының әртүрлілігімен сипатталады. Жүзге қатысты мтДНҚ (HVR1, HVR2) гипервариабелді аудандарының мутациясын талдау қазақтардың барлық аналар линияларының генетикалық туыстығын анықтайды.

Түйін сөздер: қазіргі заманғы қазақтар, мтДНҚ, HVR1, HVR2, гаплотоптар.

\section{Л. Б. Джансугурова, Г. С. Жунусова, Нуржибек,}

\section{С. А. Абдикерим, А. С. Амиргалиева, Б. О. Бекманов, Э. М. Хусаинова}

Лаборатория популяционной генетики, РГП «Институт общей генетики и цитологии» КН МОН РК, Алматы, Казахстан

\section{АНАЛИЗ КОНТРОЛЬНЫХ РЕГИОНОВ МТДНК У ЭТНИЧЕСКИХ КАЗАХОВ}

Аннотация. Проведенный анализ митохондриальных ДНК современных казахов с широкой географической локализацией и родовой принадлежностью свидетельствует, что материнские линии казахов характеризуются большим разнообразием гаплогрупп мтДНК, отражающим исторические миграции населения Евразии с преобладанием «азиатского» и «европейского» компонентов. Анализ мутаций гипервариабельных районов мтДНК (HVR1, HVR2) в отношении жузовой принадлежности определяет генетическую родственность всех материнских линий казахов.

Ключевые слова: современные казахи, мтДНК, HVR1, HVR2, гаплогруппа.

\section{Information about authors:}

Djansugurova Leyla - PhD, Institute of General Genetics and Cytology of the Ministry of Education and Science of the Republic of Kazakhstan; Almaty;leylad@mail.ru

Zhunusova Gulnur - PhD, Institute of General Genetics and Cytology of the Ministry of Education and Science of the Republic of Kazakhstan; Almaty; gulnur_j@mail.ru

Nurzhibek - master, Institute of General Genetics and Cytology of the Ministry of Education and Science of the Republic of Kazakhstan; Almaty; kahbatnur64@gmail.com

Abdikerim Saltanat - master, Institute of General Genetics and Cytology of the Ministry of Education and Science of the Republic of Kazakhstan; Almaty; abdikerim.saltanat1@gmail.com

Amirgaliyeva Almira - Institute of General Genetics and Cytology of the Ministry of Education and Science of the Republic of Kazakhstan; Almaty; almira-71@mail.ru

Bekmanov Bakhytzhan - PhD, Institute of General Genetics and Cytology of the Ministry of Education and Science of the Republic of Kazakhstan; Almaty; bobekman@rambler.ru

Khussainova Elmira - PhD, Institute of General Genetics and Cytology of the Ministry of Education and Science of the Republic of Kazakhstan; Almaty; khussainova@mail.ru 


\section{Publication Ethics and Publication Malpractice in the journals of the National Academy of Sciences of the Republic of Kazakhstan}

For information on Ethics in publishing and Ethical guidelines for journal publication see http://www.elsevier.com/publishingethics and http://www.elsevier.com/journal-authors/ethics.

Submission of an article to the National Academy of Sciences of the Republic of Kazakhstan implies that the described work has not been published previously (except in the form of an abstract or as part of a published lecture or academic thesis or as an electronic preprint, see http://www.elsevier.com/postingpolicy), that it is not under consideration for publication elsewhere, that its publication is approved by all authors and tacitly or explicitly by the responsible authorities where the work was carried out, and that, if accepted, it will not be published elsewhere in the same form, in English or in any other language, including electronically without the written consent of the copyright-holder. In particular, translations into English of papers already published in another language are not accepted.

No other forms of scientific misconduct are allowed, such as plagiarism, falsification, fraudulent data, incorrect interpretation of other works, incorrect citations, etc. The National Academy of Sciences of the Republic of Kazakhstan follows the Code of Conduct of the Committee on Publication Ethics (COPE), and follows the COPE Flowcharts for Resolving Cases of Suspected Misconduct (http://publicationethics.org/files/u2/New_Code.pdf). To verify originality, your article may be checked by the Cross Check originality detection service http://www.elsevier.com/editors/plagdetect.

The authors are obliged to participate in peer review process and be ready to provide corrections, clarifications, retractions and apologies when needed. All authors of a paper should have significantly contributed to the research.

The reviewers should provide objective judgments and should point out relevant published works which are not yet cited. Reviewed articles should be treated confidentially. The reviewers will be chosen in such a way that there is no conflict of interests with respect to the research, the authors and/or the research funders.

The editors have complete responsibility and authority to reject or accept a paper, and they will only accept a paper when reasonably certain. They will preserve anonymity of reviewers and promote publication of corrections, clarifications, retractions and apologies when needed. The acceptance of a paper automatically implies the copyright transfer to the National Academy of Sciences of the Republic of Kazakhstan.

The Editorial Board of the National Academy of Sciences of the Republic of Kazakhstan will monitor and safeguard publishing ethics.

Правила оформления статьи для публикации в журнале смотреть на сайте:

www:nauka-nanrk.kz

ISSN 2518-1629 (Online), ISSN 2224-5308 (Print)

http://www.biological-medical.kz/index.php/ru/

Редактор М. С. Ахметова, Т. М. Апендиев, Д. С. Аленов
Верстка на компьютере Д. Н. Калкабековой

Подписано в печать 11.10.2018.

Формат 60x881/8. Бумага офсетная. Печать - ризограф.

5,2 п.л. Тираж 300. Заказ 5.

Национальная академия наук $P K$

050010, Алматы, ул. Шевченко, 28, т. 272-13-18, 272-13-19 